AROUEOLogía Y SOCIEDAD

№ 25, 2012: 89-114

ISSN: 0254-8062

RECIBIDO: MARZO DE 2012

ACEPTADO: OCTUBRE DE 2012

\title{
DE ENTIERROS Y OFRENDAS: UN CEMENTERIO EN TIEMPOS NASCA, EN EL VALLE DE AJA, PERÚ
}

\author{
JuAn CARLOS De LA TORRE Zevallosi \\ UNIVERSIDAD AUTÓNOMA DE BARCELONA \\ jc.delatorre.zevallos@gmail.com
}

\section{RESUMEN}

El presente reporte describe los recientes hallazgos de un cementerio prehispánico en tiempos Nasca, en el yacimiento arqueológico de El Trigal, localizado en el valle de Aja (Nasca, Perú). La materialidad social recuperada indica una filiación cronológica con el denominado periodo Nasca Temprano (c. 50/100 a 350/400 cal DNE). Los registros arqueológicos documentan una singularidad de contextos funerarios, desde una escasa presencia de ajuares funerarios hasta los hallazgos de cuerpos desmembrados, con evidencias de agresión con arma y una cabeza cercenada. A ellos se suman el hallazgo de vasijas de cerámica, depósitos, fogones y hoyos de poste contiguos a los entierros, los cuales indican su posible asociación con prácticas políticas-ideológicas (rituales) y/o económicas. Estos hallazgos nos sugieren una lectura de relaciones asimétricas y el ejercicio de políticas de violencia física en época Nasca.

Palabras Clave: Prácticas funerarias, asimetría social, cabeza-trofeo, violencia.

\section{ABSTRACT}

The present report describes the recent findings of a pre-Hispanic cemetery in times Nasca, in the archaeological site of El Trigal, located in the valley of Aja (Nasca, Peru). The social materiality recovered indicates a chronological connection to the denominated period Early Nasca (50/100-350/400 AD). The archaeological registries document a singularity of funeral contexts, from a scarcity of grave goods to findings of dismembered bodies, with evidence of aggression with a weapon and a severed head. They are joined by the discovery of pottery vessels, deposits, hotplates and postholes adjacent to the burials, which indicate their possible association with political-ideological practices (rituals) and/or economic. These findings suggest a reading of asymmetrical relations policy and the exercise of physical violence in Nasca period.

KeYwords: Funerary practices, social asymmetry, trophy head, violence.

En 1926 A. Kroeber y E. Schenk, como parte de la expedición auspiciada por el Field Museum of Natural History de Chicago en la costa sur del Perú (Kroeber 1927, 1944; Kroeber y Collier 1998), acompañados por Julio C. Tello miembro del Museo Nacional de Arqueología por parte del gobierno peruano, localizan tres cementerios prehispánicos en el valle de Aja (Aja A, Aja B y Aja C), un afluente del río Grande, en la provincia de Nasca. Dos de ellos de ocupación tardía post-nasca y uno perteneciente

i Licenciado en Arqueología de la Universidad Nacional Mayor de San Marcos (Perú). Master en Arqueología Prehistórica de la Universidad Autónoma de Barcelona. 
al denominado periodo Nasca Temprano (Kroeber y Collier 1988; Williams et al. 2001). Es justamente Tello quien localiza los cementerios Aja A y Aja B (Kroeber y Collier 1998: 33; Tello y Mejía Xesspe 1967) -este último de factura Nasca- los cuales son excavados en conjunto de manera rápida ante la necesidad de explorar más yacimientos en la zona, incluido el de Cantayoc entre la confluencia de los valles de Aja y Tierras Blancas (Kroeber y Collier 1998). De estas excavaciones, Kroeber recupera una colección de materiales arqueológicos de la época Nasca con extraordinario valor científico (Kroeber 1944, 1957; Kroeber y Collier 1998) que ha servido de referencia y estudio para muchos otros investigadores e investigadoras (Baraybar 1987; Carmichael 1988, 1995; Coelho 1972; Forgey y Williams 2003, 2005; Knudson et al. 2009; Proulx 1989; Silverman 1993; Strong 1957; Williams et al. 2001, inter alii).

Desde aquellas excavaciones hasta la actualidad, los badilejos han sido superados por las palas clandestinas de los saqueadores de tumbas y, no menos dañina, por la creciente ampliación de campos de cultivo y zonas urbanas, que vienen destruyendo vestigios de ese pasado. Sin embargo, se han llevado a cabo trabajos de investigación en la zona que han permitido contener parte de esa destrucción y recuperar de manera científica restos de ese pasado. Así, desde las excavaciones de Kroeber y Tello (Kroeber 1944; Kroeber y Collier 1998; Tello y Mejía Xesspe 1967) en el valle de Aja, pasando por los trabajos emprendidos, posteriormente, por la Expedición Arqueológica de la Universidad de California en Berkeley en los años 1954-1955, igualmente en la costa sur del Perú, bajo la dirección de J. H. Rowe $(1956)^{1}$, hasta las investigaciones de la última década, las informaciones sobre esta parte de la provincia de Nasca, se han incrementado de manera satisfactoria. Los trabajos recientes en la zona han permitido documentar una serie de yacimientos arqueológicos de todas las épocas (cfr. Castro Martínez, De La Torre Zevallos y Escoriza 2008, 2009, 2011; Conlee 2003, 2007; De La Torre Zevallos 2005; De La Torre Zevallos y Van Gijseghem 2005; Van Gijseghem 2004, 2006; Vaughn y Van Gijseghem 2007; inter alii). No obstante, y a diferencia de los registros funerarios, tanto de áreas sepulcrales como entierros individuales, en yacimientos localizados en valles adyacentes (cfr. Isla 1992; Isla et al. 1984) y zonas cercanas, principalmente en el complejo monumental de Cahuachi (cfr. Orefici y Drusini 2003; Silverman 1993), en el valle de Nasca, los registros de cementerios en tiempos Nasca localizados hasta el momento en el valle de Aja, a pesar de la profusa evidencia que el saqueo indiscriminado ha dejado en superficie, siguen siendo muy restringidos, exceptuando algunos casos de hallazgos de entierros aislados en la zona, de singular relevancia (cfr. Conlee 2007).

En el 2001, un trabajo de reconocimiento inicial nos permitió localizar las evidencias de un cementerio Nasca, en la sección media del valle Aja (De La Torre Zevallos 2005). Posteriormente, en el 2006, dentro del marco de investigaciones del Proyecto Arqueológico La Puntilla² (De La Torre Zevallos y Castro Martínez 2007), se constató el hallazgo de dicho cementerio asignándole la denominación «necrópolis» ${ }^{3}$ de El Trigal, que de acuerdo a las evidencias asociadas mantiene una cronología relativa perteneciente al periodo Nasca Temprano (c. 50/100 a 350/400 cal DNE). Las excavaciones se realizaron entre los años 2006 y 2007 (De La Torre Zevallos y Castro Martínez 2007; Castro Martínez,

1 Rowe delegaría los trabajos de campo en el valle de Nasca a D. A. Robinson, quien analizó algunas áreas de los valles de Aja, Poroma, Tierras Blancas y Taruga (Robinson 1957).

2 Las excavaciones arqueológicas se llevaron a cabo con las autorizaciones correspondientes del entonces Instituto Nacional de Cultura del Perú. Los trabajos durante el 2006 se autorizaron por Acuerdo № 912 de la Comisión Nacional Técnica de Arqueología y con Resolución Directoral Nacional № 1907. En tanto los trabajos del 2007, recibieron la aprobación por Acuerdo № 0738 de la Comisión Nacional Técnica de Arqueología y refrendada por la Resolución Directoral Nacional № 1473 del Instituto Nacional de Cultura del Perú.

3 La palabra «necrópolis» ha sido utilizada como sinónimo del término cementerio y no en toda su extensión etimológica, pues las reducidas dimensiones espaciales del conjunto excavado en El Trigal no corresponden con el ideal sugerido para tal término. Sin embargo, el uso reiterativo de éste término a lo largo del texto responde a la utilización de tal denominación en todo el registro arqueológico que se llevó a cabo en el yacimiento excavado y referenciado en anteriores reportes (Castro Martínez, De La Torre Zevallos y Escoriza 2008, 2009 y 2011). 
De La Torre Zevallos y Escoriza 2008, 2009). Sin embargo, ha sido en la campaña del 2008 cuando se ha profundizado en la sistematización de los registros y descripciones analíticas de los conjuntos bioarqueológicos, de manera que se dispone de la caracterización de todos los restos humanos documentados (Godoy 2007, 2008; Urízar y Castellanos 2009). Esto ha permitido completar la identificación de los individuos (número de individuos, sexo, edad) y obtener una visión en conjunto de la población que se enterró en las sepulturas de este cementerio.

En el presente reporte describimos los hallazgos de la denominada necrópolis de El Trigal, dando énfasis a su emplazamiento arquitectónico, las estructuras funerarias, la manipulación de cuerpos y los objetos materiales asociados. Teniendo como base esta nueva información, discutimos, mediante comparativas análogas (pre)históricas y sociales, las implicancias de estos hallazgos en las dinámicas sociales de la ocupación Nasca en la zona. Y con el fin de aportar nuevos conocimientos -en clave sociológica- acerca de las prácticas funerarias de época Nasca, planteamos algunas interrogantes en su interpretación.

\section{LA «NECRópolis» DE El Trigal (NASCA, ICA)}

El yacimiento de El Trigal, situado en la costa sur del Perú (Fig. 1), se ubica en la margen izquierda del valle del río Aja, aproximadamente dos kilómetros, valle arriba, del sitio de La Puntilla y casi a $7 \mathrm{~km}$ de la actual ciudad de Nasca. Sus coordenadas UTM son: 513600 E y 8362850 N. La altitud del terreno varía en esta zona entre los 740 hasta los $820 \mathrm{msnm}$. Las precipitaciones en esta zona son sumamente escasas y no llegan a los $3 \mathrm{~mm}$ de promedio anual, ambiente ideal para la conservación natural de restos orgánicos. Sin embargo, lamentablemente, la cercanía a zonas de cultivo y posibles filtraciones de agua subterránea, cercanas a dicha necrópolis, han alterado la buena conservación de los restos hallados.

El área central del yacimiento corresponde a un asentamiento temprano (c. 600 cal.- 150 cal. ANE) (De La Torre Zevallos y Castro Martínez 2006, 2007; Castro Martínez, De La Torre Zevallos y Escoriza $2008,2009,2011$ ) que ocupa la cima (sector I o ZCI) y las laderas (sector II o Z01) de un pequeño cerro rocoso que sobresale del macizo de La Puntilla, la cadena montañosa que asciende hacia las primeras estribaciones de los Andes (Fig. 2). Éste se encuentra flanqueado, al este y oeste, por dos torrenteras o quebradas secas que le otorgan cierto aislamiento. Atravesando estas quebradas, al noreste, continúa la cadena de cerros, en cuyas laderas bajas se estableció el área del cementerio (sector III o zona necrópolis ZNC).

La «necrópolis» (ZNC) abarca un espacio aproximado de más de $600 \mathrm{~m}^{2}$. Ocupa la parte baja de un pequeño saliente de la cadena de cerros. Las excavaciones en el lugar permitieron documentar áreas bien definidas y delimitadas con muros de piedra (Fig. 3), de forma cuadrangular y orientadas en eje noreste-suroeste: un emplazamiento principal o terraza mayor, sobre el cual se distribuyen un área intermedia sobreelevada de forma natural y una plataforma menor al noreste (Fig. 4), además de una serie de estructuras aterrazadas, más al norte, que constituyen parte del conjunto arquitectónico del lugar.

El emplazamiento arquitectónico principal (terraza mayor) está delimitado por dos muros de contención (EMP 1 al noroeste y EMP 2 al suroeste) de gran envergadura que se juntan formando la esquina suroeste del mismo. Estos muros están hechos de gruesos cantos rodados (piedras traídas probablemente de las inmediaciones del cauce del río Aja) y alzados a manera de pirca sin uso de argamasa.

Si bien el área principal -la terraza mayor- comprende espacios exclusivos de enterramiento, con mayor concentración de tumbas en la esquina sureste (Fig. 4), los muros de contención antes mencionados que la delimitan no precisan con seguridad una filiación cronológica certera con la necrópolis; esto debido al hallazgo, durante las excavaciones, de alfarería temprana del Periodo Inicial 


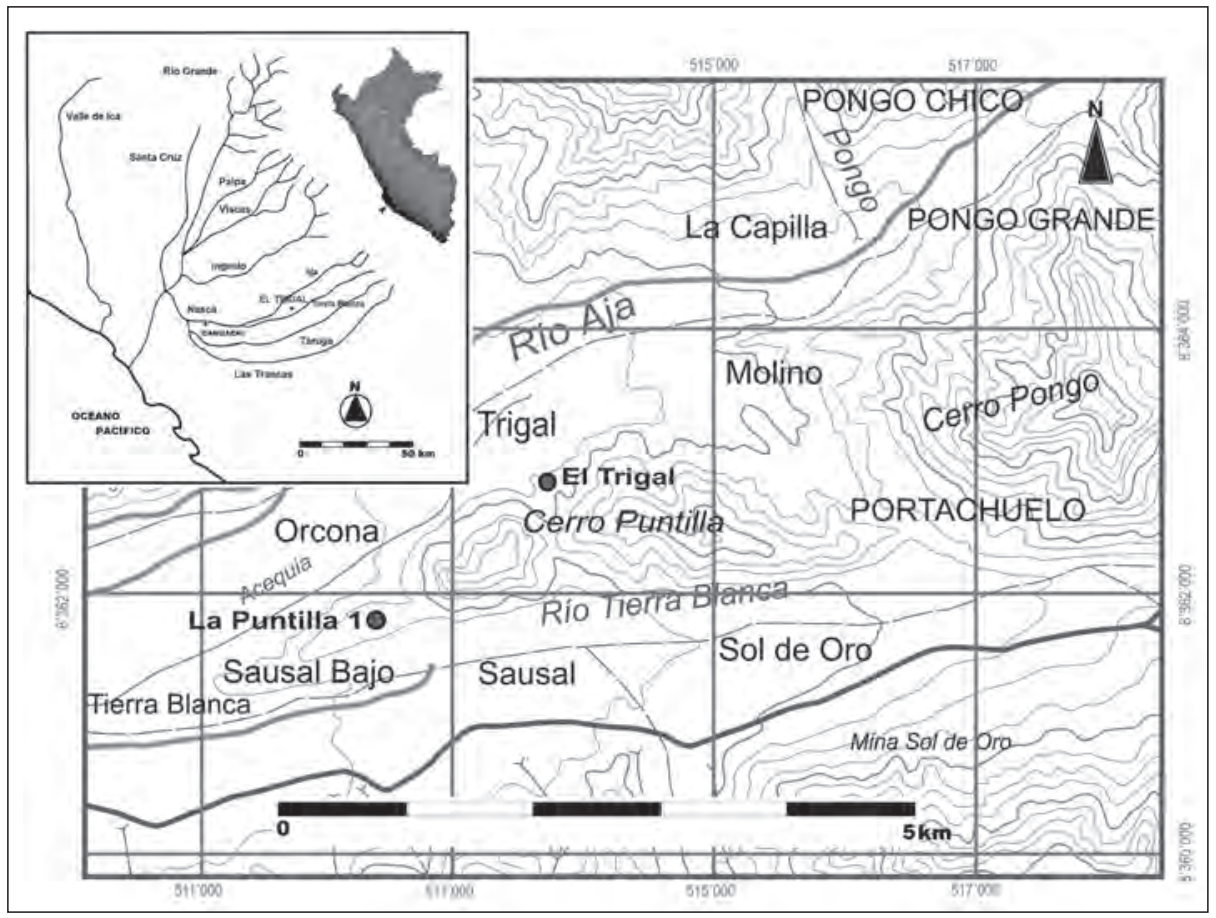

Figura 1. Mapa de la costa sur del Perú y localización del yacimiento de El Trigal en el valle de Aja (Nasca) (Dibujo: J. Ponce y J.C. De La Torre).

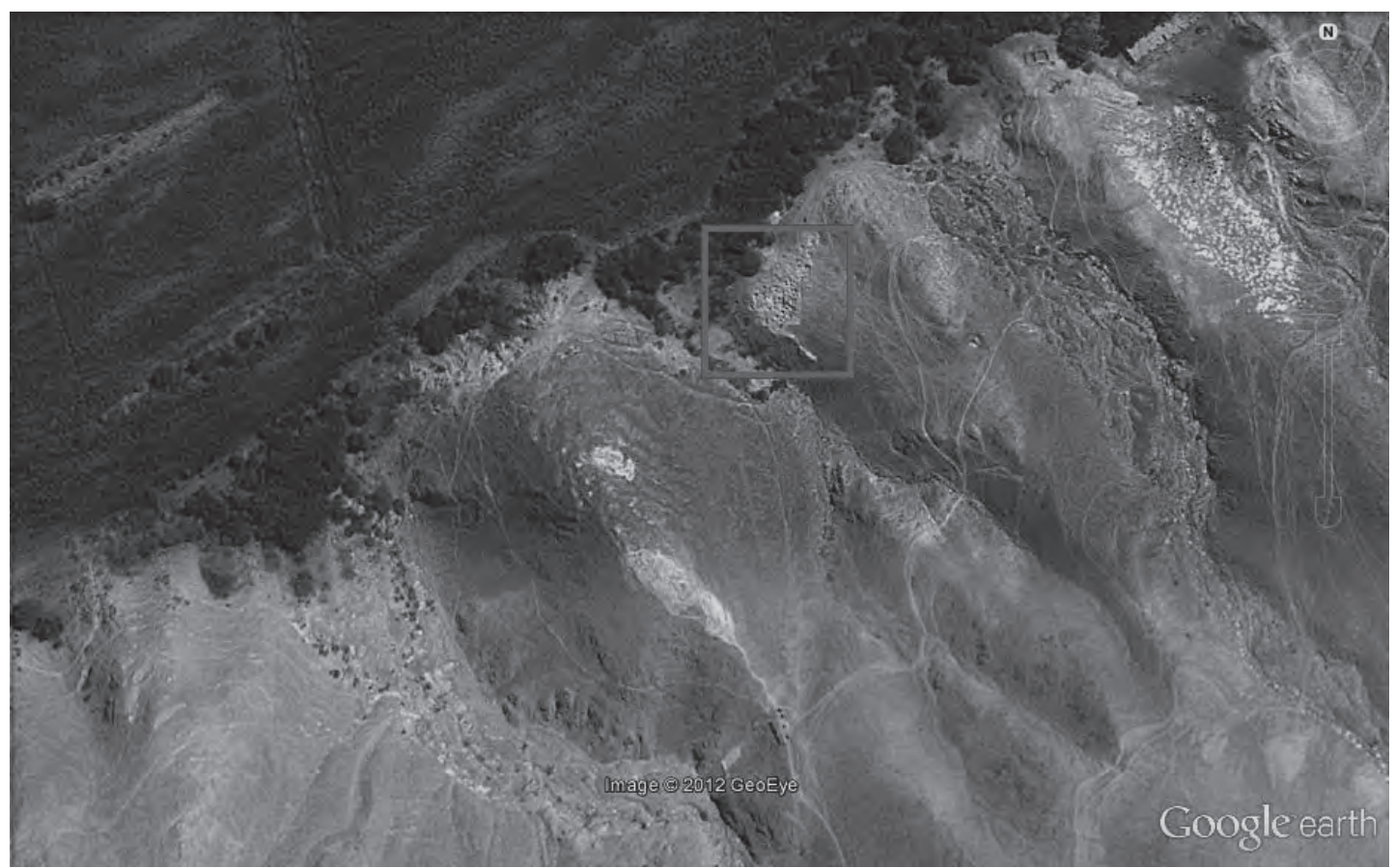

Figura 2. Foto aérea del yacimiento de El Trigal y recuadro del cementerio de tiempos Nasca (zona necrópolis ZNC) (Fuente: Google Earth). 


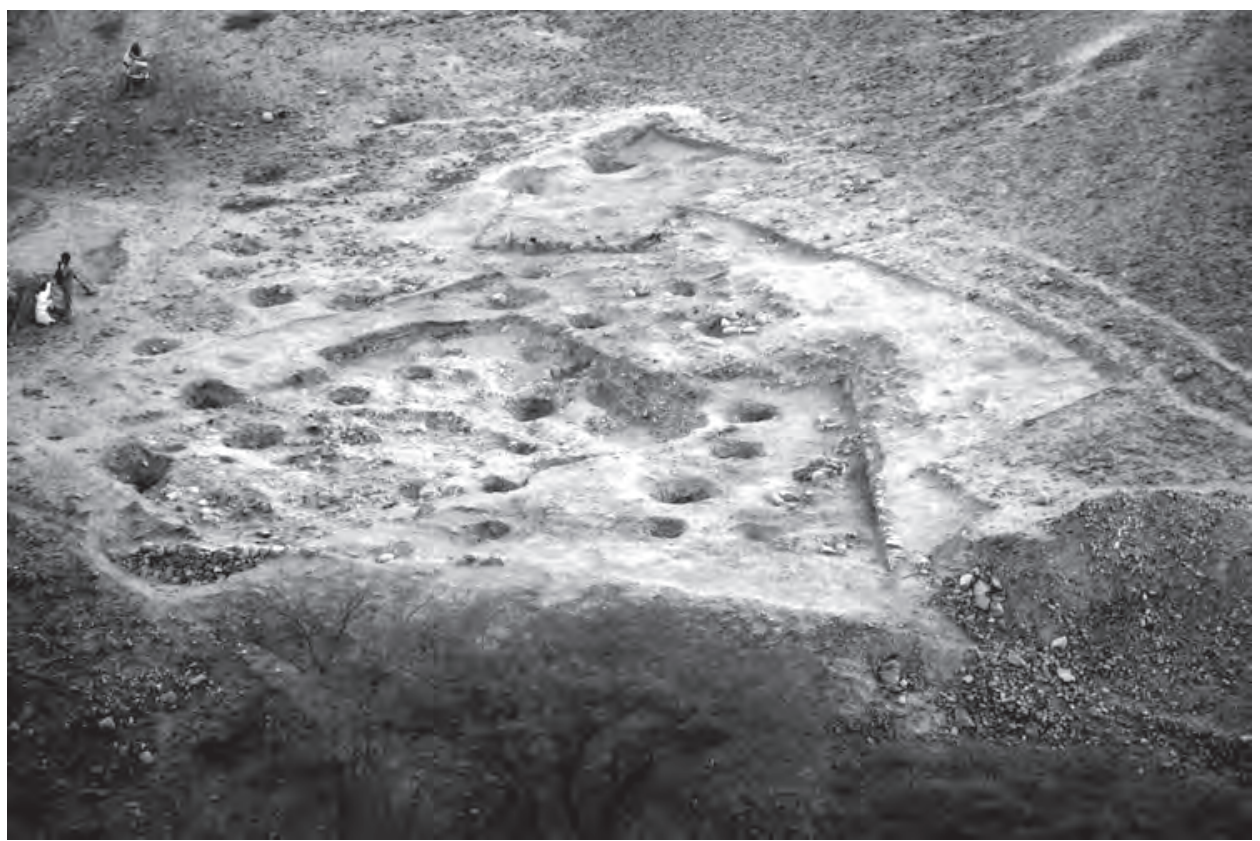

Figura 3. Vista panorámica de las excavaciones en la zona necrópolis de El Trigal.

(Fig. 5) en los estratos inferiores de la misma (Castro Martínez, De La Torre Zevallos y Escoriza 2008). Sin embargo, la construcción del muro periférico que delimita el lado sureste (EMP 9) (Fig. 6) de la terraza mayor, corrobora el emplazamiento arquitectónico de la necrópolis, pues se levanta sobre el suelo social que sirvió de soporte a las prácticas funerarias realizadas en el lugar. Igualmente, en la plataforma cuadrangular noreste, estructura medianamente elevada por muros de contención, situada en el interior del emplazamiento principal, se han documentado los cimientos de un muro de barro (EMT 1) entre el relleno constructivo, en su extremo lateral NE, estructura aún por definir si anterior o coetánea a los espacios funerarios de la necrópolis. Considerando estas evidencias, es probable que la construcción de la necrópolis se estableciera sobre espacios estructurados más tempranos, acondicionando sobre ellos espacios funerarios exclusivos y vinculantes para tal fin.

Además de los entierros, la documentación de una serie de depósitos, fogones y hoyos de poste, ubicados de forma dispersa en todo el recinto funerario y en algunos casos también concentrados en áreas específicas del mismo (Fig. 4), nos han permitido identificar espacios relacionados con actividades probablemente vinculadas a las prácticas funerarias; aunque no descartamos la existencia de otro tipo de actividades asociadas a posibles unidades habitacionales que pudieron configurar eventuales espacios domésticos al interior de la misma necrópolis. La mayor concentración de depósitos se localiza en el área intermedia del emplazamiento principal, al este, acotando, conjuntamente con los hoyos de poste, un área contigua a las áreas funerarias. Muchos de los depósitos se encuentran horadando la superficie natural del terreno, sin ningún tipo de aditamento constructivo (Fig. 7a). Lamentablemente, aún no disponemos información acerca del tipo de contenido que pudieron almacenar dichos depósitos; es probable que contuvieran algún tipo de restos orgánicos cuya descomposición ha impedido, por el momento, su identificación. En cuanto a los fogones, éstos aparecen en asociación con los depósitos y adyacentes a los espacios de entierro (Fig. 7b). Algunos de éstos se encuentran ligeramente estructurados (demarcados con piedras) y otros simplemente se identifican por la superficie de quema intensa. Por último, los hoyos de poste se distribuyen de forma regular (Fig. 7c), sobre todo acotando una parte del área intermedia sobreelevada en asociación con los depósitos y algunas áreas de combustión. 


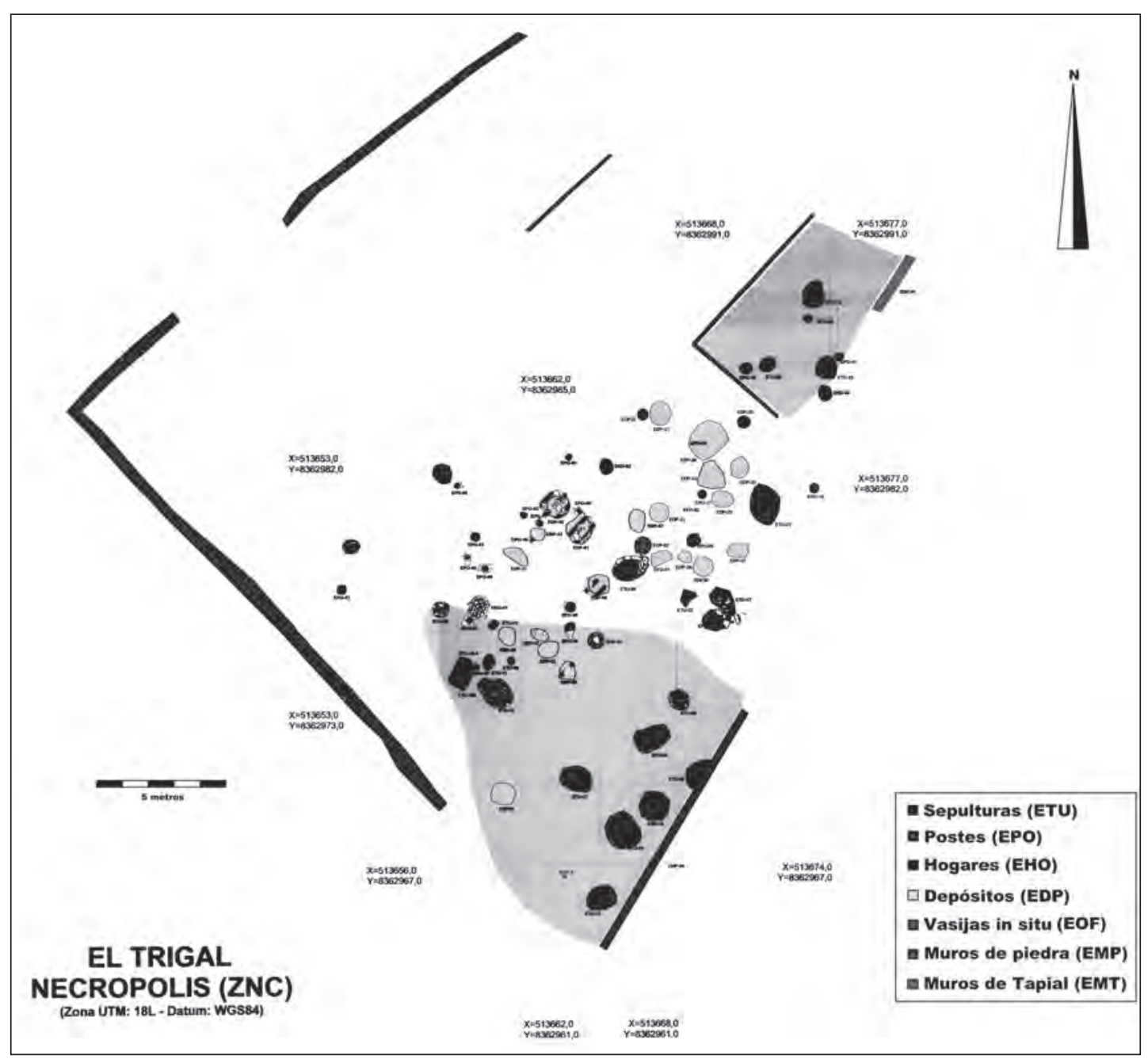

Figura 4. Plano topográfico con localización de los contextos funerarios $y$ otros hallazgos en la necrópolis de El Trigal.

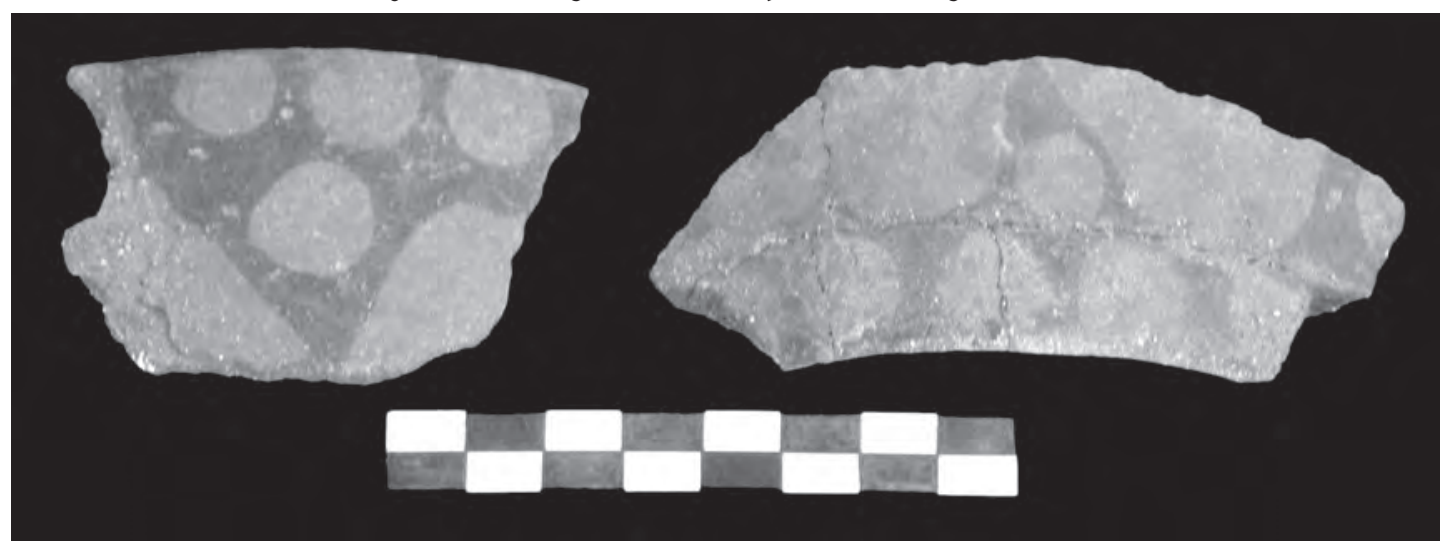

Figura 5. Cerámica con decoración negativa del Período Inicial encontrada en la necrópolis de El Trigal. 


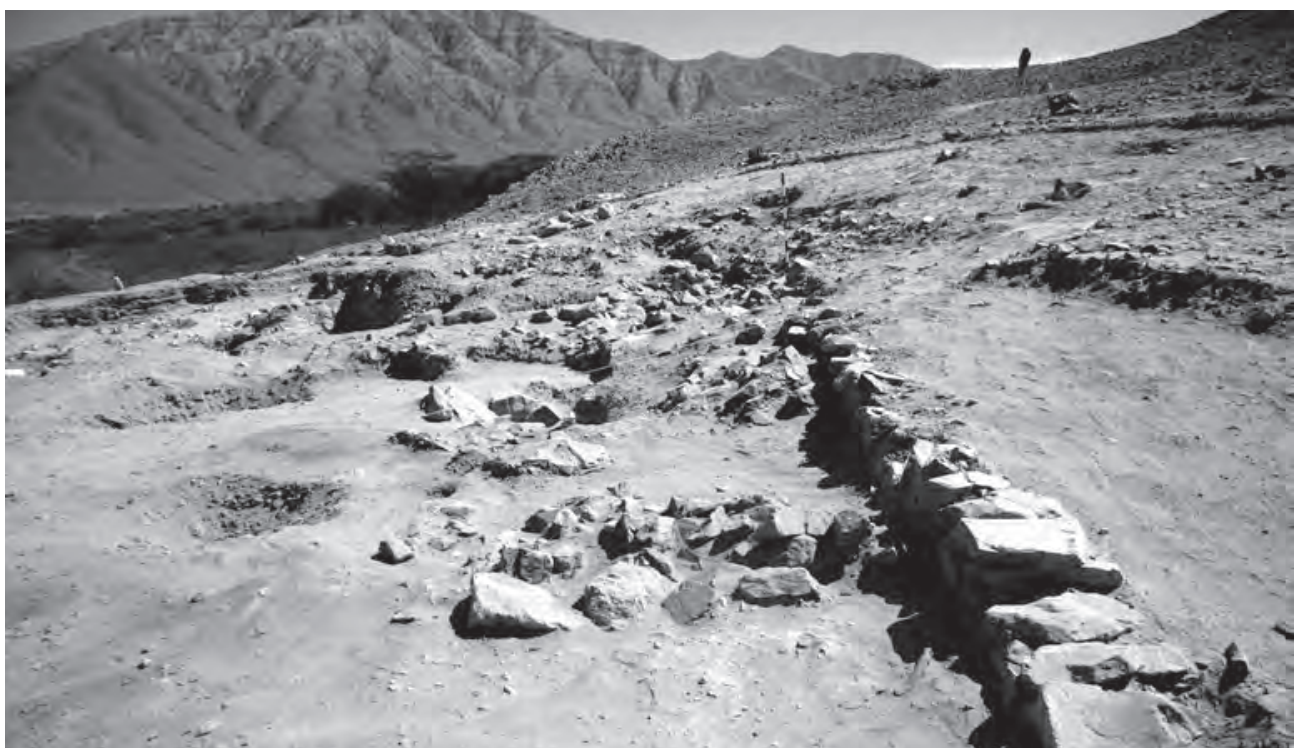

Figura 6. Detalle del muro 9 (EMP 9) que delimita el lado sureste (SE) de la necrópolis de El Trigal.
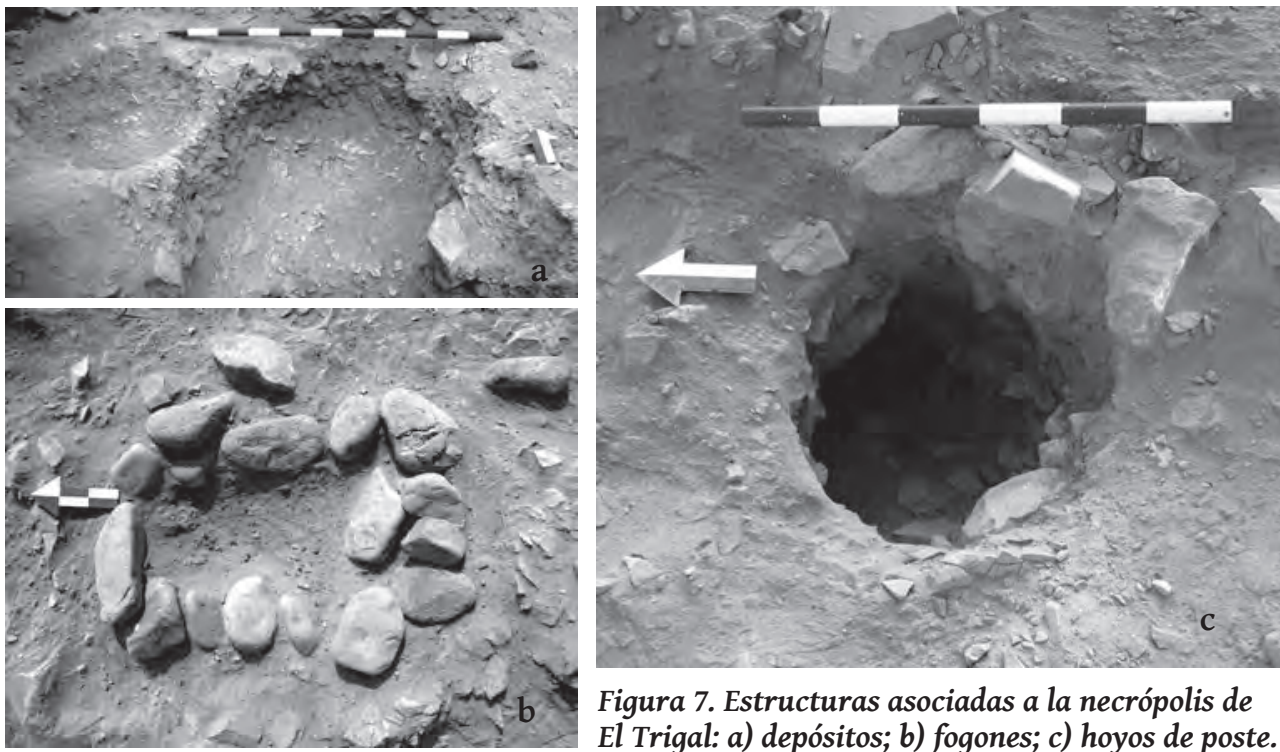

Figura 7. Estructuras asociadas a la necrópolis de El Trigal: a) depósitos; b) fogones; c) hoyos de poste.

\section{DE LOS ENTIERROS}

\section{a. Las tumbas}

Los tipos de tumbas encontrados en la necrópolis comprenden distintas variantes, tales como: pozos simples, pequeñas cámaras laterales con acceso de pozo (tipo «bota») y urnas cerámicas (Fig. 8). Muchas de ellas, aunque no necesariamente todas, presentan un sello de piedras acumuladas, incluido cantos rodados, con un ligero mortero de barro en la superficie de la boca como señal o marcador de tumba y, excepcionalmente, algunos bloques de barro compacto. Los restos materiales (cerámicos) (Fig. 9) asociados a los sellos, rellenos y suelos donde se establecieron las sepulturas, mantienen una filiación cronológica con el periodo Nasca Temprano. 
Las sepulturas en pozo simple o fosas son las de mayor recurrencia en la necrópolis (Fig. 8.a). Presentan una planta de forma ovalada y una estructura cilíndrica, cuyos diámetros varían entre 1,10 m y 0,60 m y alcanzan una profundidad entre $0,90 \mathrm{~m}$ y $0,35 \mathrm{~m}$. Las fosas más pequeñas y de escasa profundidad, en su mayoría corresponden a entierros de individuos neonatos (ETU 1, ETU 8 y ETU 9) ${ }^{4}$. En algunos casos presentan un ligero acomodo de piedras (tipo lajas y cantos rodados) en la boca de los pozos y en otros una estructuración simple de piedras en las paredes internas (revestimiento) sobre la cual recostaban al individuo. Además, en algunas de las tumbas, se observó el acomodo de vigas de huarango (Prosopis sp.) sobre la boca de las mismas (ETU 3, ETU 10 A y ETU 10 B), que en muchos casos colapsó al interior debido a la presión de los rellenos que lo cubrían.

En el caso de la sepultura tipo «bota» (ETU 13) (Fig. 8b), presenta una estructuración de acceso simple en pozo con el acondicionamiento de una cámara lateral abierta en el fondo (subterráneo), lo cual le otorga la forma en cuestión. La cámara, al igual que el pozo de acceso, se encuentran horadando las capas naturales y roca madre, presentando un ligero acomodo de piedras en la boca de la cámara y en el interior, previo a la colocación del individuo. La estructura total alcanza un diámetro de $1.10 \mathrm{~m}$ por 0.90 $\mathrm{m}$ de profundidad, reduciéndose la cámara final a 0,60 $\mathrm{m}$ de diámetro por 0,45 $\mathrm{m}$ de profundidad.

La única urna de cerámica (Fig. 8.c) hallada en la necrópolis corresponde al hallazgo del cráneo de un individuo, o cabeza cercenada, colocado en el interior de una vasija de cerámica (ETU 15) cubierta con una tapa de piedra tipo laja (De La Torre Zevallos 2012). La sepultura en el fondo de la cual se colocó la urna presenta una estructuración en pozo simple de 0,75 $\mathrm{m}$ de diámetro por 0,86 $\mathrm{m}$ de profundidad. La vasija es una olla globular de 0,32 $\mathrm{m}$ de diámetro con restos de hollín en sus paredes y la boca rota ex profeso para la colocación del cráneo en su interior.

Las tumbas en pozos simples o fosas, las de mayor número en la necrópolis, han sido localizadas de manera dispersa sobre las diversas áreas documentadas. En tanto, la tumba tipo «bota» y la sepultura en pozo con urna se han ubicado en el área sureste de la terraza mayor, en una zona exclusiva delimitada por el muro EMP 9, junto a otras tumbas en pozo.

\section{b. Los individuos}

Entre los años 2006 y 2007 se realizó un examen preliminar de los restos bioantropológicos (Godoy 2007 y 2008), retomándose el análisis en el 2008 (Urizar y Castellanos 2009). Esto nos ha permitido verificar, corregir y contrastar adecuadamente los análisis llevados a cabo y, por ende, afinar adecuadamente los resultados para el presente reporte. En total se ha registrado un número mínimo de 48 individuos (Urizar y Castellanos 2009), aunque únicamente 17 han sido hallados en contextos funerarios no alterados -sobre cuyo análisis se estructura el presente reporte-, lo que permite estimar que el $65 \%$ de las sepulturas fueron destruidas por saqueos en las excavaciones clandestinas. El registro por sexo y edad de los individuos adultos y subadultos procedentes de las sepulturas no alteradas y que han podido ser determinados - por un total de 10 individuos- ha confirmado una presencia mayor de hombres en contraste a las mujeres. Igualmente, siempre entre los individuos procedentes de las sepulturas no alteradas, se ha podido precisar la existencia de enterramientos infantiles menores de 1 año de edad, neonatos, en cantidad considerable con respecto a los demás entierros, gracias a su buena preservación in situs. Sin embargo, la determinación del sexo para este grupo no ha podido realizarse por los problemas implícitos en el análisis de restos óseos de esta edad. También parece que ningún individuo encontrado sobrepasó los 40-45 años, edad que supondría el límite de la es-

$4 \quad$ ETU= Estructura de tumba o sepultura.

5 Lamentablemente, los restos óseos de este grupo, durante el embalaje y traslado, no soportaron adecuadamente su manejo. Sin embargo, se logró analizar buena parte de la muestra recuperada, tanto in situ como los restos que lograron llegar a laboratorio. Considerando esta situación, los primeros análisis llevados a cabo de este grupo (Godoy 2007, 2008) han sido tomados como principal referente para el presente reporte. 


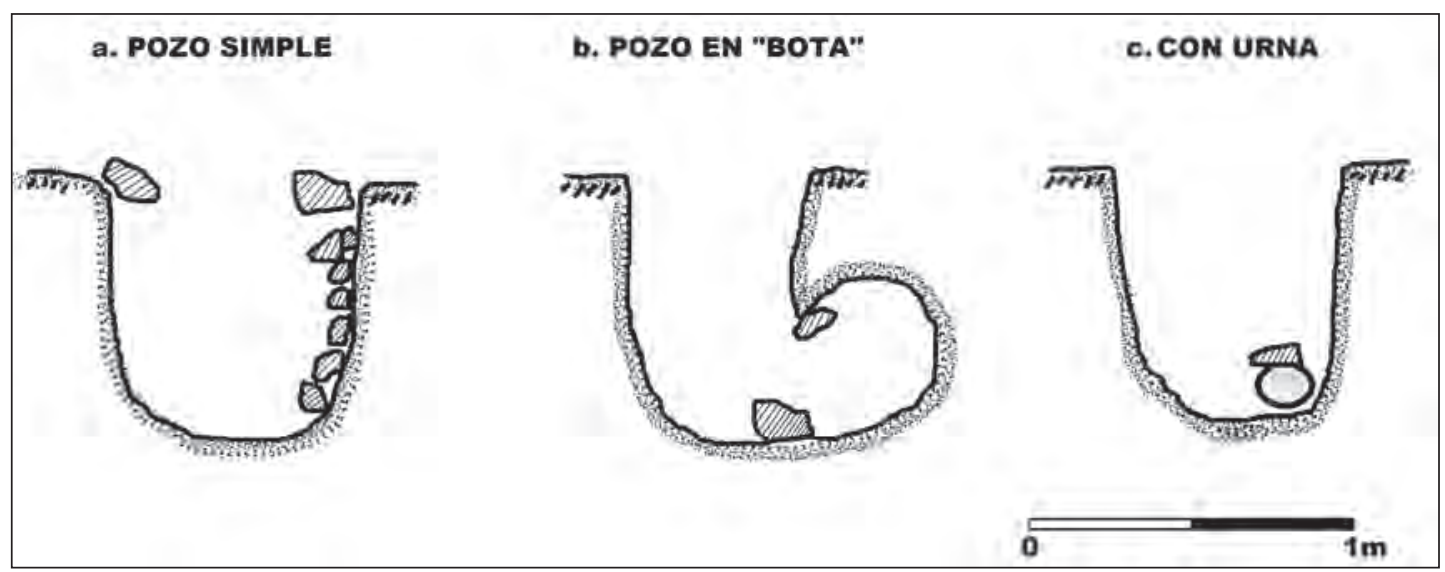

Figura 8. . Tipos de tumbas localizadas en la necrópolis de El Trigal: a) pozo simple; b) en «bota»; c) con urna.
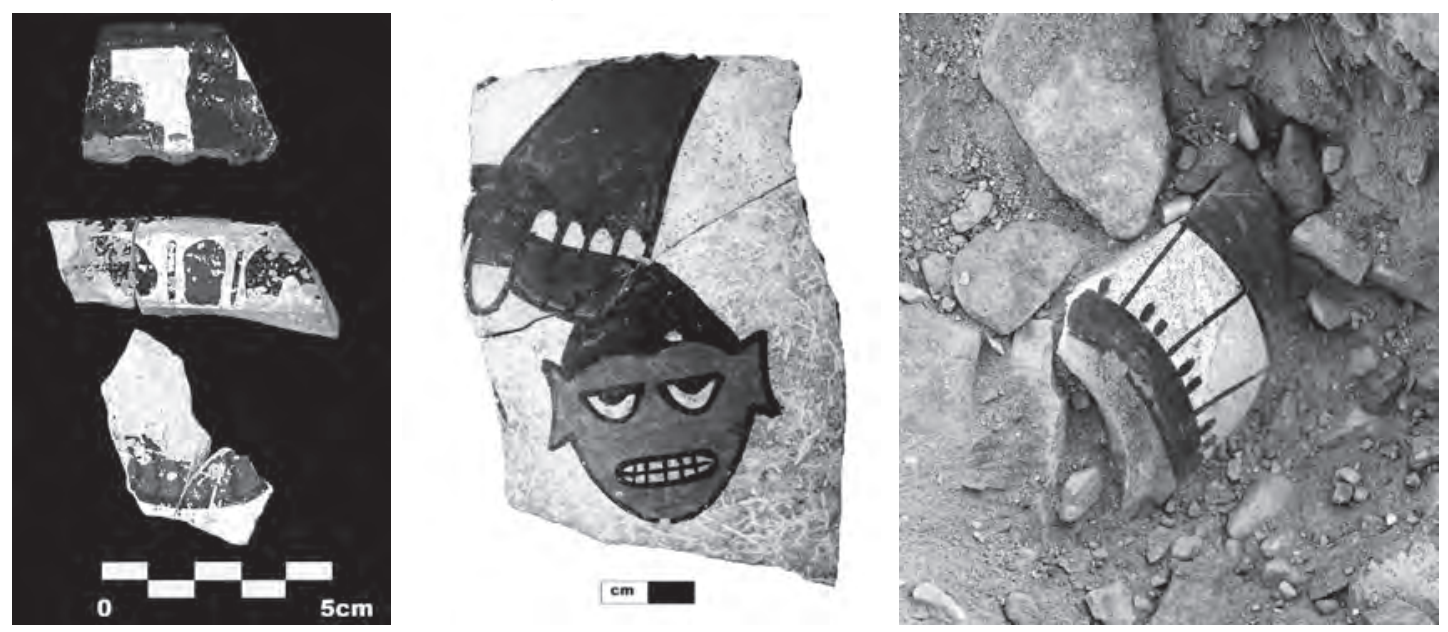

Figura 9. Fragmentos de cerámica Nasca Temprano asociados a las sepulturas y al área funeraria de El Trigal.

peranza de vida en los horizontes cronológicos de la necrópolis (Fig. 10a). No obstante, la población representada en su totalidad -entre los entierros disturbados y no disturbados-ofrece un porcentaje de supervivencia por encima de los 20-30 años, lo que alcanza el 70\% de individuos de edad determinable; mientras que la mortalidad infantil, incluyendo los individuos neonatos, representa el $30 \%$ de los casos documentados (Fig. 10b).

Las tumbas de individuos neonatos (ETU 1, ETU 8 y ETU 9) (Fig. 11) se concentran sobre la superficie de la terraza mayor, cerca del área intermedia de la necrópolis. Éstos fueron enterrados de forma individual en fosas simples con un diámetro no superior a los 0,40 $\mathrm{m}$ y una profundidad máxima de $0,35 \mathrm{~m}$; en algunos casos se ha observado la presencia de un ligero acomodo de piedras en la boca de las mismas, sobre todo con mayor incidencia en la sepultura ETU 9. Ninguno de los individuos encontrados sobrepasa los 9 meses de edad (Godoy 2008). Los cuerpos presentan una cierta orientación hacia el noreste y están colocados tanto en posición fetal con las piernas flexionadas (ETU 9), como sentados con las piernas extendidas (ETU 1). Sólo la tumba ETU 9 presenta un ajuar funerario compuesto por un collar de cuentas de moluscos (Spondylus sp.) posicionado en la altura superior del tronco del individuo, cerca del cráneo. 

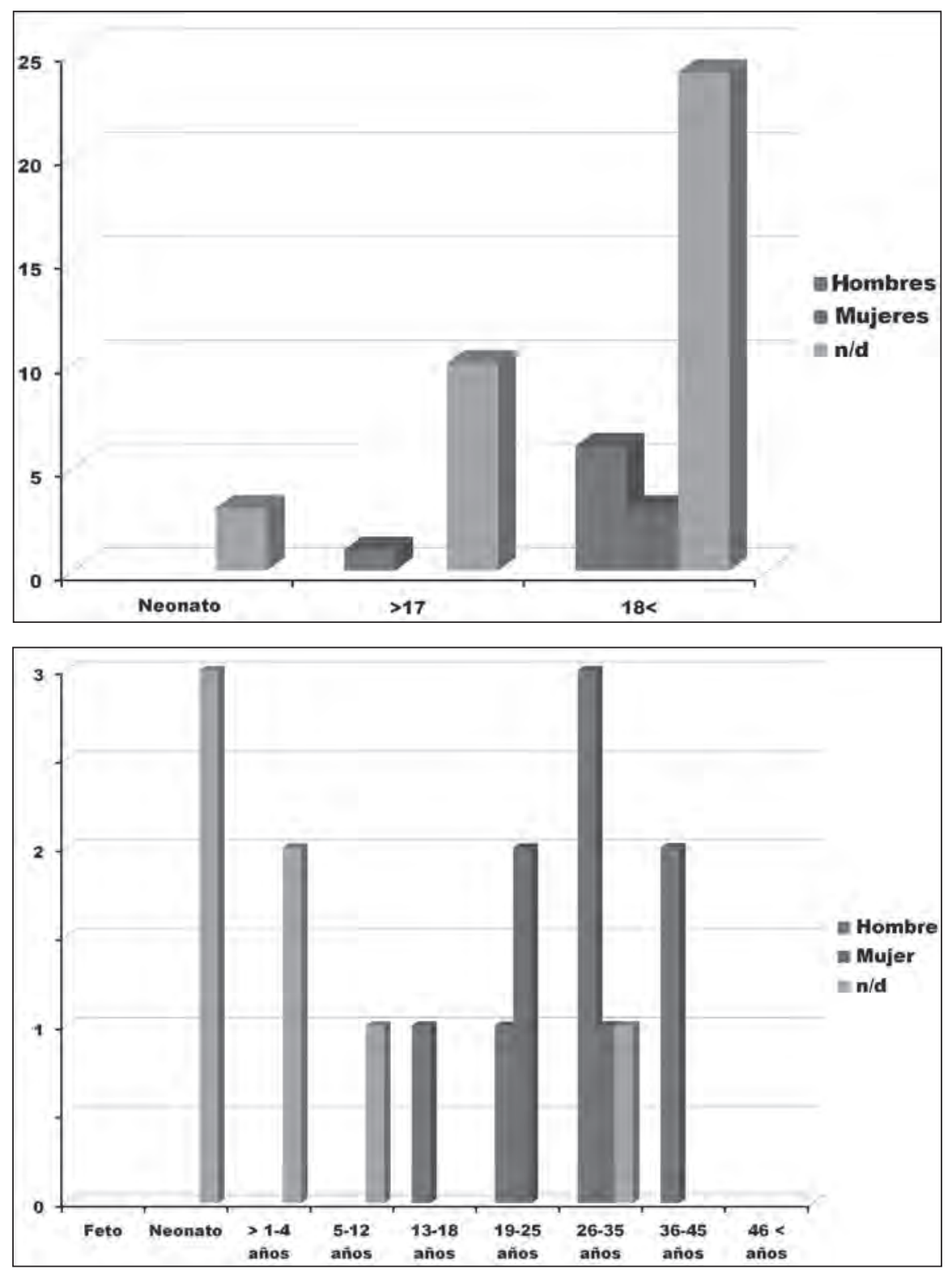

Figura 10. Cuadros de distribución de los individuos identificados en la necrópolis de El Trigal (tumbas intactas y disturbadas): a) Tabla de distribución por edad; b) Tabla de distribución por sexo (Fuente: Godoy 2007, 2008; Urízar y Castellanos 2009).

Los entierros infantiles, mayores de un año y/o subadultos (ETU 11, ETU 16, ETU 20 y ETU 22) (Fig. 12), no ocupan un área determinada; se encuentran dispersos en toda el área de la necrópolis. Los individuos presentan edades fluctuantes entre los 2-5 años y 12-15 años. La posición y orientación de los cuerpos no refleja un patrón definido, aunque destaca la posición sentada con las piernas flexionadas y las manos proyectadas hacia la cavidad ventral y/o rostro, en los individuos de más edad, mientras que el individuo de la tumba ETU 22 presenta los brazos extendidos sobre y debajo de las piernas 
flexionadas. Igualmente a los demás, estos entierros infantiles son de forma individual pozo simple o fosa. Tres de los cuatro entierros presentan un acomodo de piedras en la boca y al interior de la fosa, además de un cúmulo de piedras angulares y cantos rodados como sello o señal de las tumbas. La única presencia de ajuar funerario hallado en este grupo corresponde a un collar de moluscos (caracolas de mar) (Bulla sp. y Turritella sp.) (Fig. 13) asociado al entierro ETU 22, un infante de aproximadamente 5 años de edad.

El individuo de la tumba ETU 16, un varón cuya edad oscila entre los 12 y 15 años, presenta una deformación craneana de tipo anular, no muy pronunciada, caracterizada por una bóveda craneal alargada y tubular, como resultado de la compresión circunférica de los huesos frontal, temporal, parietal y occipital por medio del uso, quizá, de bandas gruesas apretadas a modo de turbante, o también de la aplicación de tablillas y almohadillas (Allison et al. 1981). En tanto, en el entierro ETU 20 (Fig. 14), al interior de una estructura intacta con anillo de piedras en la boca, se han encontrado los restos sin cráneo de un infante de alrededor 4 años de edad. La articulación ósea del individuo se encontraba intacta, y el cuerpo en posición sentada y con las piernas flexionadas. No obstante, el análisis preliminar señala la ausencia de indicios de corte en las vertebras cervicales, aunque éstas no están completas -sobre todo aquellas que se articulan con las partes desprendidas-, lo que nos lleva a plantear un probable cercenamiento postmortem.

En cuanto a las tumbas de individuos adultos, igualmente, se encuentran ocupando, de forma proporcional, todas las áreas de la necrópolis. Destaca un número mayor de hombres, 6 individuos, en relación a las mujeres, las cuales se reducen a 3 individuos determinados. A excepción de las tumbas ETU 10A y ETU 10B (Fig. 11), que parecen constituir una tumba doble, la mayor parte de los individuos fueron enterrados de manera individual, en pozos simples, $y$, de forma excepcional, en fosa con cámara lateral subterránea (tipo «bota») (ETU 13) y en urna de cerámica (ETU 15). En casi todas es-

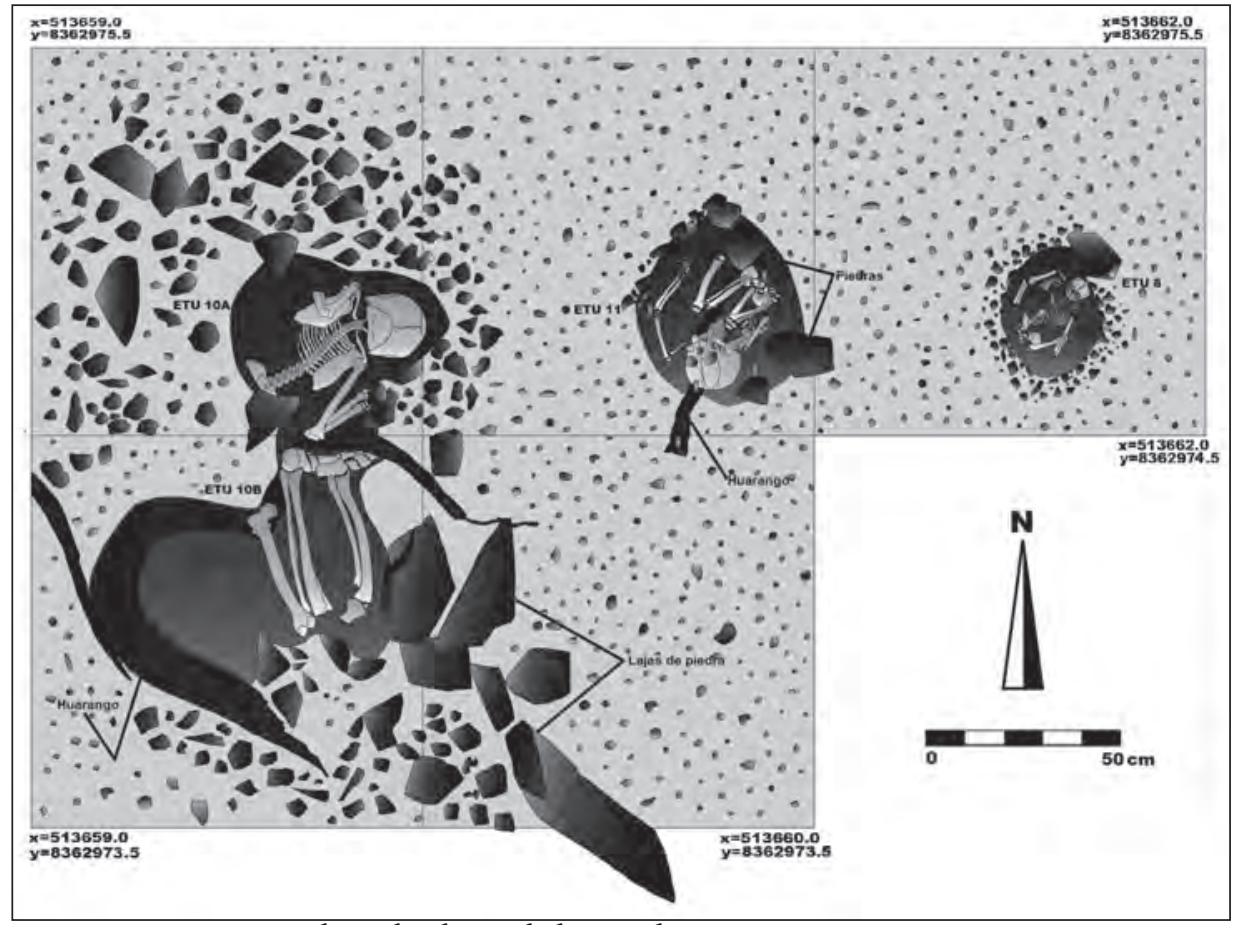

Figura 11. Dibujo de planta de las tumbas ETU 8, ETU 10A, ETU 10B y ETU 11 de la necrópolis de El Trigal (Dibujo: M.C. Godoy). 


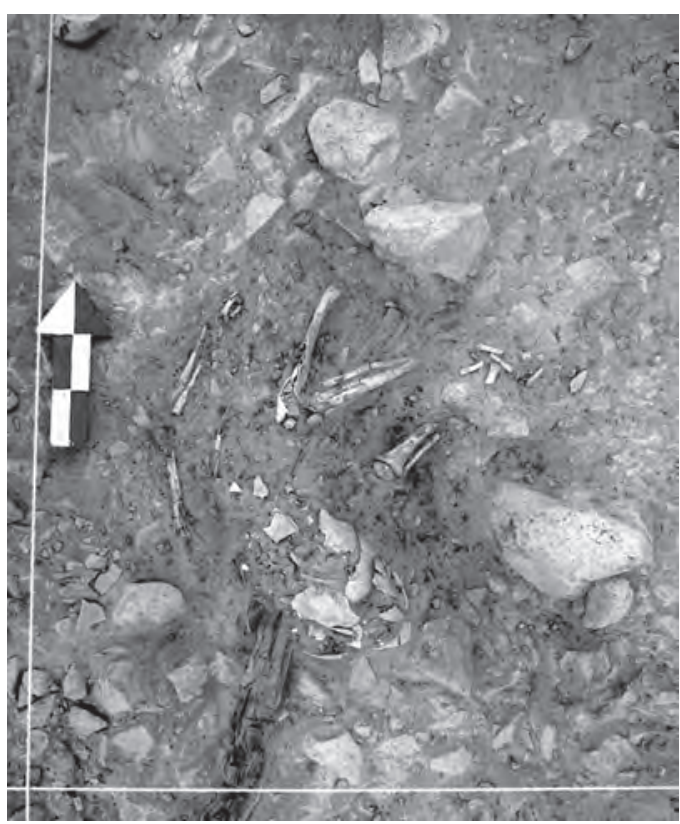

Figura 12. Individuo (infante) de la tumba ETU 11 de la necrópolis de El Trigal.

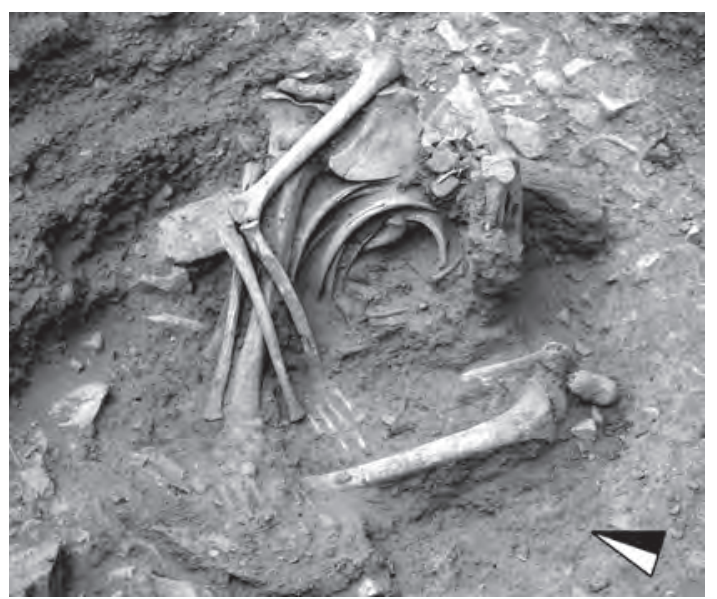

Figura 14. Individuo (infante) sin cabeza encontrado en la tumba ETU 20 de la necrópolis de El Trigal.

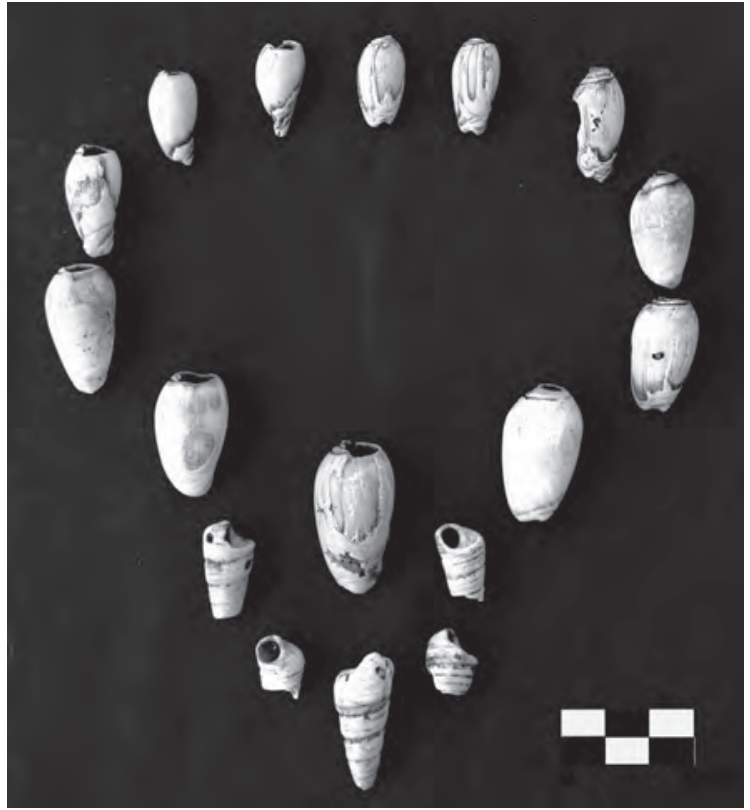

Figura 13. Collar de moluscos marinos encontrado en la tumba ETU 22 de la necrópolis de El Trigal.

tas sepulturas se observa la presencia del cúmulo de piedras a manera de sello o señal de tumba. Los cuerpos no presentan un patrón de orientación determinado, aunque destaca la tendencia hacia el norte. En cuanto a la posición, los individuos se encuentran sentados o recostados lateralmente con las piernas y brazos flexionados hacia el pecho y las manos proyectadas hacia la cavidad ventral y/o rostro. Sólo en dos tumbas se ha registrado la presencia de ajuar funerario: una olla pequeña de cerámica con fuerte evidencia de desgaste por uso en la tumba ETU 17 y restos de un roedor pequeño (Cavia sp.) cubierto con un grueso fragmento de cerámica en la tumba ETU 15.

Además, en este grupo de individuos se ha documentado un mayor índice de manipulación de los cuerpos de forma específica, como deformaciones craneanas, cabezas separadas del tronco y desmembramientos (ETU 3, ETU 13, ETU 10B y ETU 15) y la constatación de un caso de agresión por armamento (punta de flecha) (ETU 21).

En el caso de los individuos de las tumbas ETU 3 (estructura en pozo) (Fig. 15) y ETU 13 (estructura en «bota») (Fig. 16), ambos de sexo masculino y con edades fluctuantes entre los 30 y 35 años para el primero, y alrededor de los 40 años en el segundo, presentan una deformación craneana tipo anular similar al individuo de la tumba ETU 16, aunque más acentuadas. Ambos fueron colocados en posición fetal con las piernas hiperflexionadas y los brazos entre las piernas y el pecho, es decir, en la cavidad 

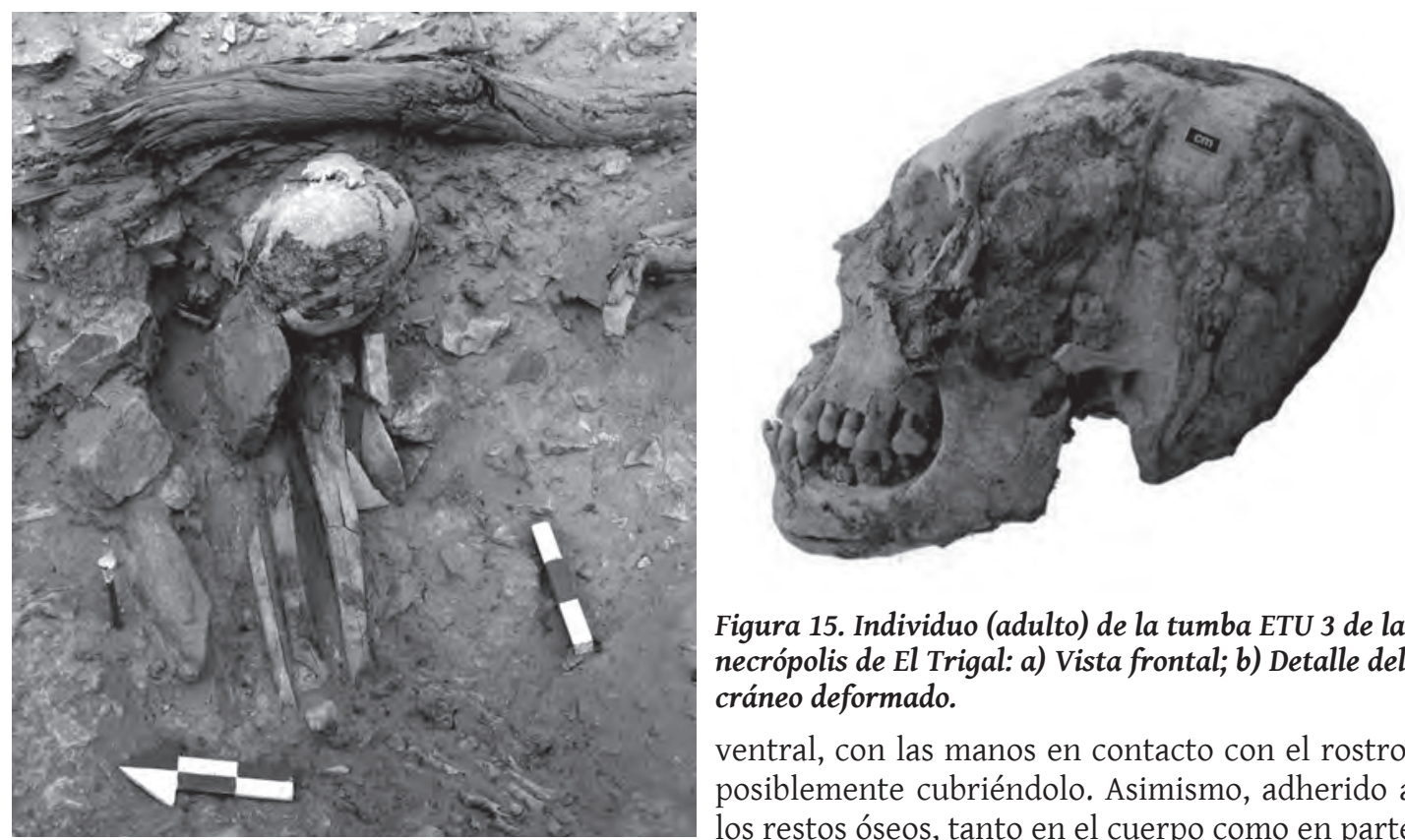

Figura 15. Individuo (adulto) de la tumba ETU 3 de la necrópolis de El Trigal: a) Vista frontal; b) Detalle del cráneo deformado.

ventral, con las manos en contacto con el rostro, posiblemente cubriéndolo. Asimismo, adherido a los restos óseos, tanto en el cuerpo como en parte del cráneo, se han detectado restos de fibra vegetal y textil, muy deteriorados, que formarían parte del posible enfardelamiento o vestuario -con posible turbante en el cráneo- de los difuntos durante el entierro. Otros casos de deformación craneana, menos pronunciadas e igualmente anulares, se han observado en los individuos de las tumbas ETU 17 (Fig. 17) y ETU 18 (Fig. 18).

La tumba ETU 10B (Fig. 11) contenía restos de un individuo desmembrado. Sólo se han hallado las extremidades inferiores (fémures, tibias, peronés y huesos de los pies) de forma flexionada y
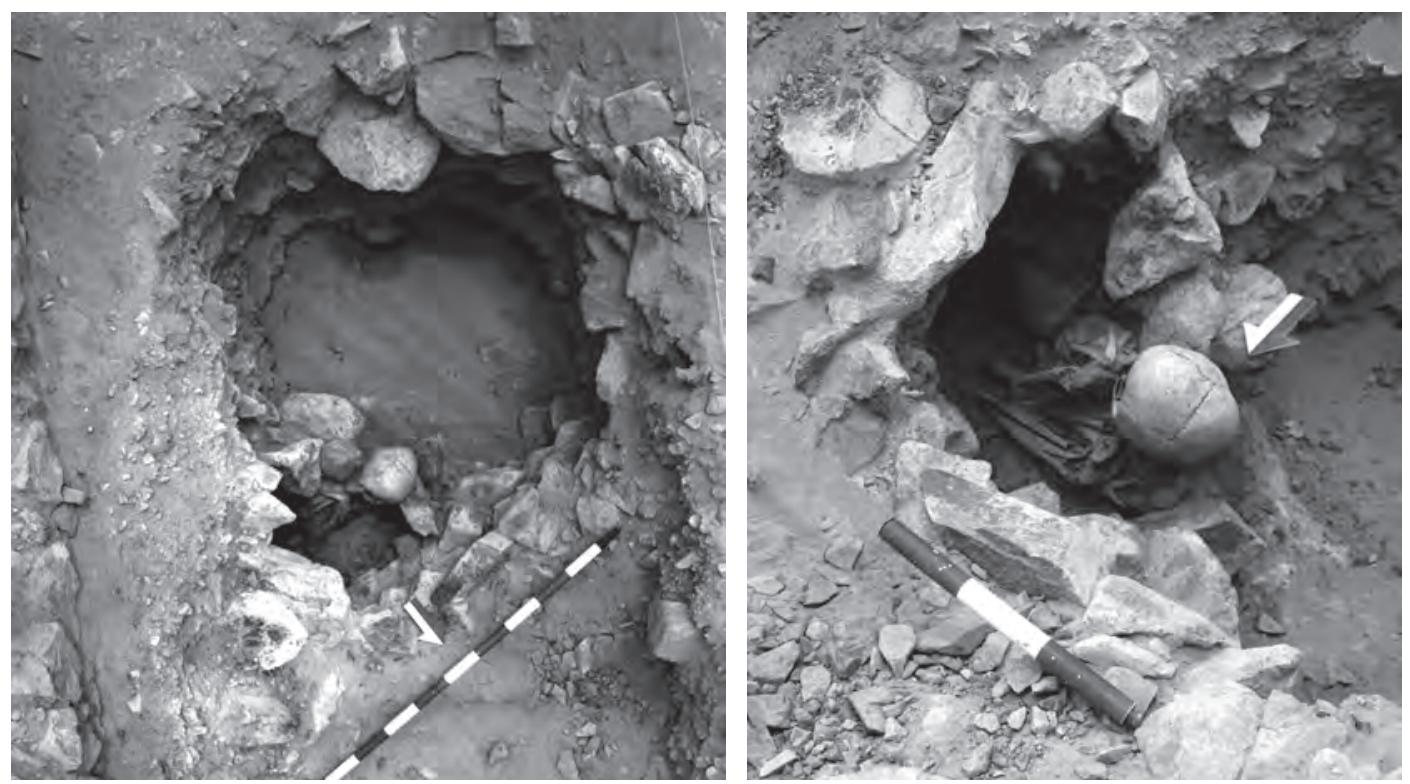

Figura 16. Individuo (adulto) de la tumba ETU 13 de la necrópolis de El Trigal: a) Vista de planta de la estructura funeraria; b) Detalle de la cámara lateral y cráneo. 


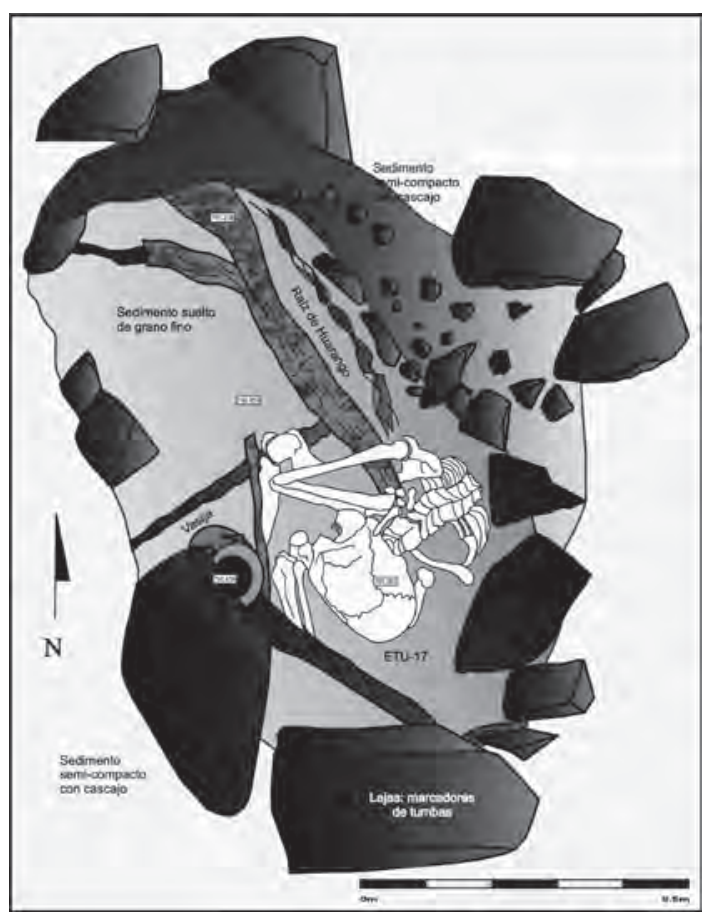

Figura 17. Dibujo de planta de la tumba ETU 17 de la necrópolis de El Trigal (Dibujo M.C. Godoy).
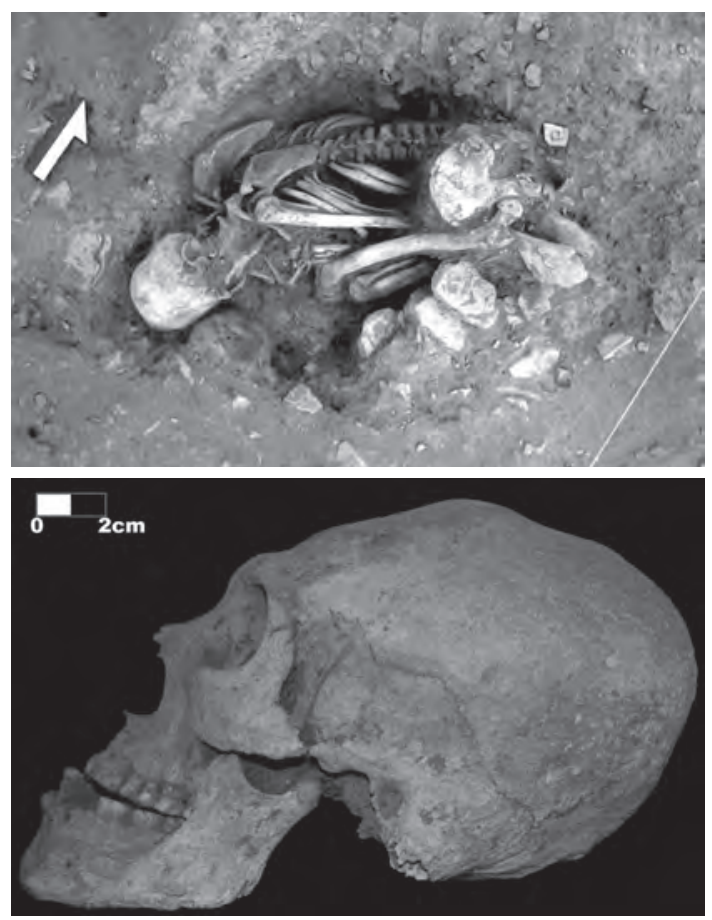

Figura 18. Individuo (adulto) de la tumba ETU 18 de la necrópolis de El Trigal: a) Vista de planta; b) Detalle del cráneo deformado.

muy bien articuladas. Los análisis preliminares señalan la ausencia de marcas de cortes en las epífisis proximales que, aunado al deterioro de las mismas, impide asegurar con certeza la naturaleza del desmembramiento. Sin embargo, la buena conservación de los restos óseos in situ -aunque no de la estructura que se encontraba dañada en superficie- señala que la separación de la parte superior del cuerpo se hizo cuando aún conservaban tejido blando, sin precisar si inmediatamente o después de la muerte del individuo (Godoy 2008: 202). Estos restos se han encontrado en un pozo que se adosaba a otro (ETU 10A) con acomodo de troncos de huarango, conjuntamente con un individuo completo de sexo femenino, cuyo cuerpo estaba en posición ventral y con las piernas flexionadas.

Al interior de la estructura ETU 15 (Fig. 19), una tumba en pozo, ha sido hallada una urna de cerámica (supra) que contenía los restos de una cabeza cercenada (De La Torre Zevallos 2012). El cráneo presenta un orificio de pequeñas dimensiones y borde irregular, en el hueso frontal. Los huesos temporales y el occipital presentan fragmentación y ausencia de algunas porciones óseas, siendo la parte basal la más ausente. Quizá la ausencia de estas partes óseas faltantes del cráneo se deba posiblemente al uso prolongado del mismo como objeto singular. Estas evidencias confirman el hallazgo de una "cabeza trofeo», sobre todo por la presencia del orificio frontal y la ausencia de la parcialidad basal, lo cual suele ser diagnóstico en el tratamiento de estas cabezas (Verano 2001, 2003).

Finalmente, en la tumba ETU 21 (Fig. 20) -una estructura intacta en pozo y con un anillo de piedras grandes en la boca- se ha documentado otro cuerpo desmembrado de un individuo masculino, cuya edad oscila entre los 30 y 35 años. Este individuo presenta sólo parte del tronco y las extremidades superiores, muy bien articuladas y en buen estado de preservación. El cuerpo fue colocado en posición ventral con un brazo extendido hacia la zona ventral y el otro flexionado con proyección de la mano hacia el pecho. Los análisis bioantropológicos preliminares no han detectado marcas de cor- 

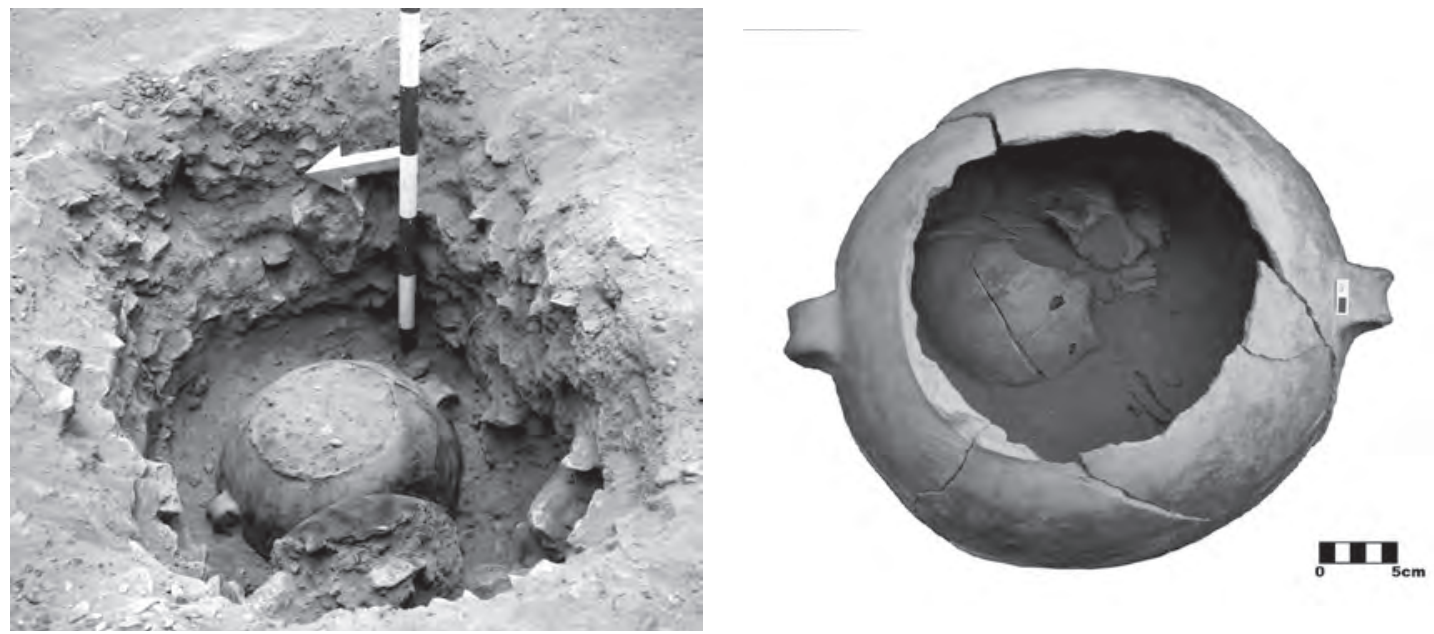

Figura 19. Urna funeraria ETU 15 de la necrópolis de El Trigal: a) Vista de la urna al interior del pozo; b) Detalle del cráneo al interior de la urna.

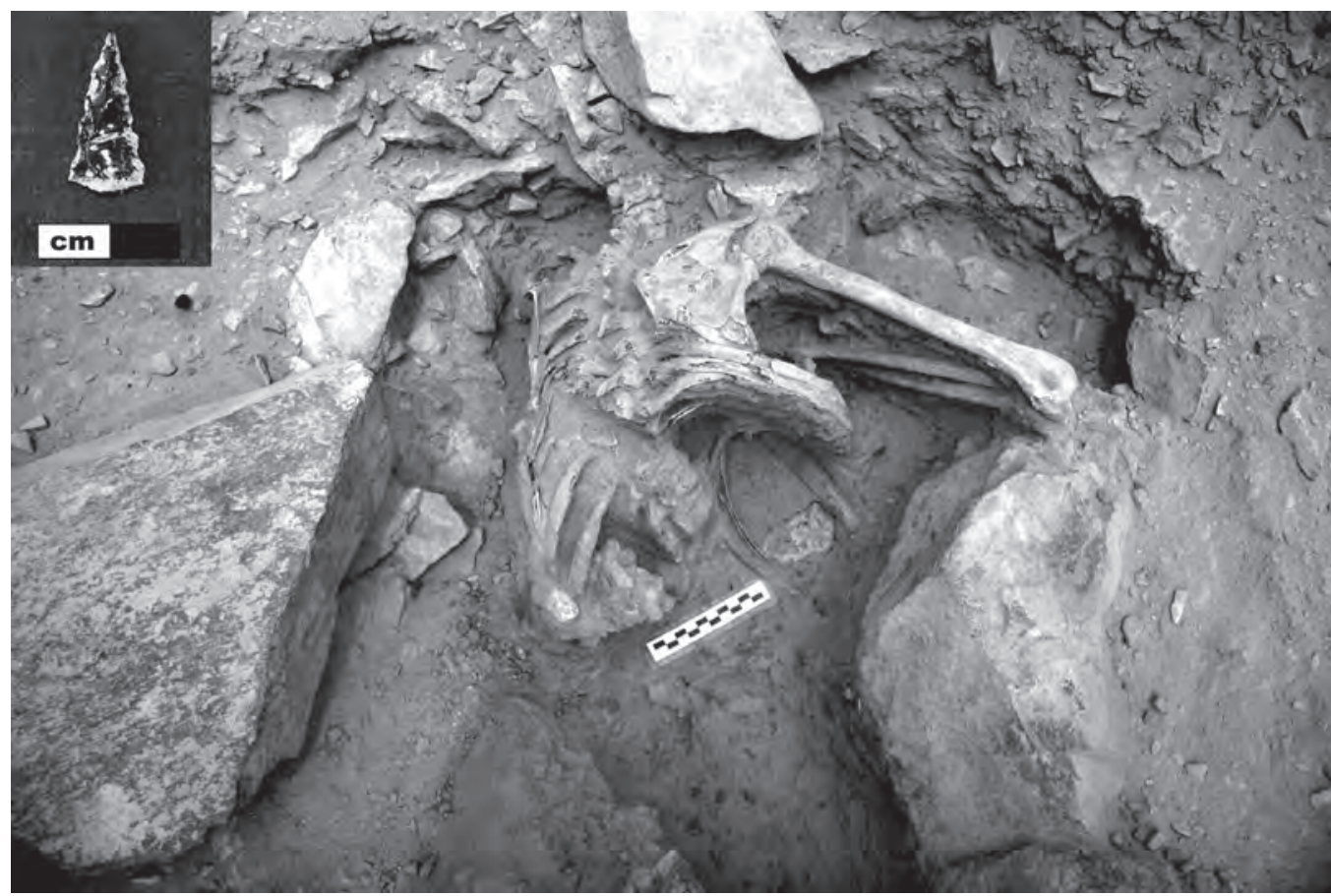

Figura 20. Individuo (adulto) desmembrado de la tumba ETU 21 de la necrópolis de El Trigal y detalle de la punta de obsidiana que estuvo incrustada a la altura del esternón del individuo.

tes en las articulaciones desprendidas, aunque se repite la ausencia de restos óseos que se articularían con éstas. Además, a la altura del esternón se ha hallado incrustado el resto de una punta de obsidiana bifacial (punta de flecha). El punto de impacto de la flecha, por la orientación de la misma hacia la cara interna del esternón, parece indicar que la lesión fue causada desde la superficie posterior del cuerpo, alcanzando la flecha al individuo desde atrás, es decir, dorsalmente, aunque la mala conservación de la escápula no ha permitido confirmar esta hipótesis. En cuanto a la lesión y el evento de muerte del 
individuo, nos llevan a señalar una probable vinculación de ambas a partir del hallazgo de la punta de proyectil en la cavidad torácica, sin embargo, es discutible asegurar de forma fehaciente la causa de la muerte.

\section{DE LAS OFRENDAS}

La escasa presencia de ajuares funerarios al interior de las tumbas registradas, además de la simplicidad de las estructuras funerarias, nos lleva a inferir que la población de la necrópolis de El Trigal no contaba con una riqueza destacable, en comparación con otras tumbas mejor elaboradas (en cuanto contenedor) y más notables (en cuanto a contenido), registradas en yacimientos contemporáneos de la zona (cfr. Kroeber y Collier 1988; Orefici y Drusini 2003; Silverman 1993), e indudablemente, a diferencia de las tumbas aristocráticas del periodo Nasca Medio, localizadas al norte de la cuenca del río Grande (cfr. Isla y Reindel 2006; Isla 2009). Sin embargo, dentro del perímetro del cementerio, asociados a los niveles estratigráficos de los sepulcros, se han encontrado tres vasijas de cerámica, depositadas de forma individual, en pozos a poca profundidad (entre 0,40 m y 0,60 m). Dos de estas vasijas (EOF 1 y EOF 2) ${ }^{6}$ fueron localizadas cerca del área intermedia y una tercera (EOF 3) en el extremo sureste del emplazamiento principal o terraza mayor. Esto permite sugerir una vinculación directa de estas vasijas con la deposición de bienes rituales u ofrendas, aunque por la ubicación aislada de las mismas con respecto a los entierros documentados, no parece tratarse de elementos de ajuar que acompañen a una sepultura en concreto, sino dispuestas para el conjunto funerario en general.

La vasija EOF 1 (Fig. 21a), corresponde a una olla de forma globular y cuello corto, de 0,32 m de diámetro por 0,36 $\mathrm{m}$ de altura. La parte superior del cuerpo se hallaba rota. La pared externa de la vasija no presenta decoración alguna, sino leves capas de tiznados por hollín que indican su contacto con áreas de combustión. Una laja de piedra hallada sobre su boca pudo constituir una tapa del recipiente. Igualmente, la vasija EOF 2 (Fig. 21b) es una tinaja sin decoración, de cuerpo esférico y base ligeramente cónica, con $0,38 \mathrm{~m}$ de diámetro por $0.52 \mathrm{~m}$ de altura. Esta vasija es la de mayor tamaño en comparación a las demás encontradas. Por último, la olla asignada como EOF 3 (Fig. 21c-d) ha sido hallada distante de las anteriores. Se trata de una vasija pequeña (0,20 m de diámetro) sin decoración, de cuerpo globular, base ligeramente cónica y cuello corto. Al igual que la vasija EOF 1, la presencia de hollín intenso en la pared externa apunta un contacto prolongado con áreas de combustión.

Estos recipientes fueron usados probablemente en el desarrollo de actividades ceremoniales que podrían haber tenido lugar en las áreas de enterramiento y posteriormente ofrendados a la necrópolis en su conjunto; aunque tampoco descartamos su posible uso en otras actividades (p.e. económicas) desarrolladas al interior del espacio funerario.

Por último, no se ha determinado, por el momento, el contenido de las vasijas. Sin embargo, el tamizado y flotación de las tierras contenidas en las mismas señalan la presencia de algún tipo de material orgánico descompuesto. Además, las formas de las vasijas, nos sugieren su uso como recipientes para contener o conservar bebidas o cualquier otro tipo de alimento procesado o por procesar.

\section{DisCUSIÓN Y COMENTARIOS}

Los estudios referentes a las prácticas funerarias Nasca (cfr. Carmichael 1988, 1995, Isla y Reindel 2006; Isla 2009; Kroeber y Collier 1998; Orefici y Drusini 2003; Silverman 1993) coinciden en señalar un patrón regular en la caracterización de sus sepulturas. Así, se asume, de manera generalizada, que existe una diferenciación tipológica -conocida- en la estructuración de las tumbas, una posición recurrente de los individuos -sentado/flexionado (Fig. 22) - y la presencia, modesta u ostentosa, de ofrendas o ajuar funerario. Al respecto, H. Silverman (1993), a partir de sus trabajos en Cahuachi, señalaba que

$6 \quad$ EOF= estructura con ofrenda. 

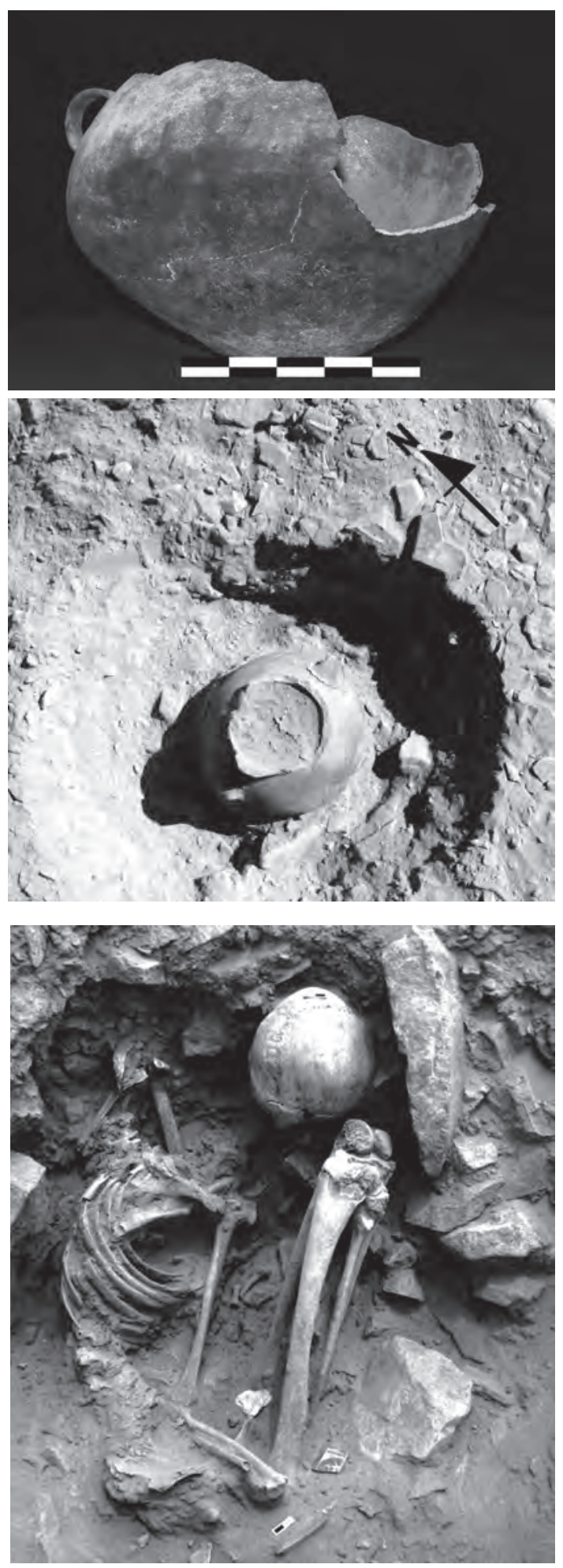
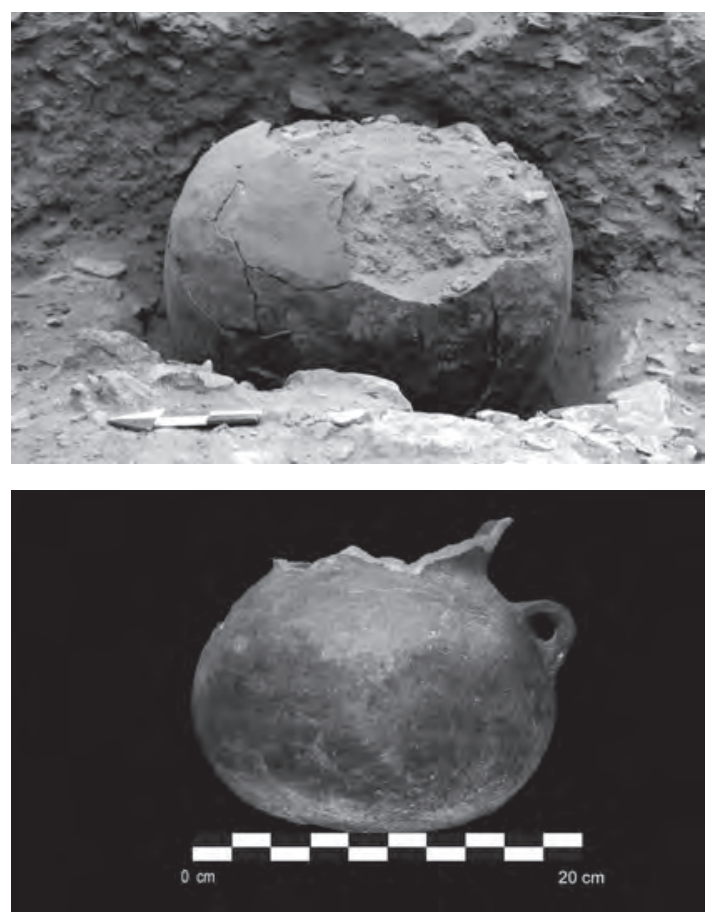

Figura 21. Vasijas de cerámica de la necrópolis de El Trigal: a) EOF 1 (en laboratorio); b) EOF 2 (in situ); c) EOF 3 (in situ); d) EOF 3 (en laboratorio).

la excepción a esta norma o patrón generalizado, posiblemente fuera resultado de la naturaleza inusual de la muerte del individuo o debido, quizá, a los actos que éste habría cometido en vida (y contribuido a su muerte), denominando a estos entierros con el término «bad deaths» (Silverman 1993: 215). Asimismo, P. Carmichael $(1988,1995)$ en su extenso trabajo de patrones funerarios Nasca, siguiendo esta línea de alejamiento del patrón recurrente, anotaba la existencia de entierros secundarios -además de otras características singulares y categorías sociales-, producto de la alteración intencional de algunas tumbas -y que por consiguiente afectaron su configuración primigenia- como consecuencia, en gran parte, de las prácticas rituales de «reingreso» («reentered») o renovación de ofrendas (Carmichael 1988). Esta práctica, según Carmichael, revolvería el contexto original de las tumbas, tanto de la

Figura 22. Individuo (adulto) de la tumba ETU 19 de la necrópolis de El Trigal, en posición sentado con las piernas flexionadas. 
colocación de las ofrendas como la destrucción de las mismas, además de la perdida de secciones de osamentas del individuo, y por lo tanto explicaría los hallazgos de individuos incompletos y, quizá, la ausencia de ofrendas en los distintos contextos funerarios analizados, sin descartar tampoco como causa de todo eso el suceso de posibles saqueos ocurridos en tiempos pre-hispánicos. Interpretaciones que merecerían una mayor profundidad de análisis de acuerdo a la fiabilidad de los contextos funerarios Nasca registrados hasta el momento.

En el caso de la necrópolis de El Trigal, la heterogeneidad de los contextos funerarios, en cuanto a estructuración de las tumbas, contenido artefactual (ajuar), tratamiento de los muertos, entre otros, marca pautas internas de caracterización individual entre ellos. Además, aunque la mayoría de los contextos funerarios documentados responden al patrón regular Nasca, se pueden apreciar algunos elementos en concreto que, alejándose de dicho patrón, marcan la diferencia y confieren singularidad a la necrópolis de El Trigal.

Las evidencias hasta la fecha consideran que el patrón regular Nasca, a nivel de estructuración de las tumbas, presenta tres categorías: entierros en pozo o fosa, en urna funeraria y en cámaras o «barbacoa» (Carmichael 1988; Isla y Reindel 2006: 379). Las tumbas en pozo o fosa son estructuras simples excavadas en capas naturales o cortando suelos sociales; algunas veces presentan acondicionamiento de paredes de barro o piedras, y de manera excepcional techos de cañas o madera (Carmichael 1988; Isla y Reindel 2006; Isla 2009). Las urnas son ollas de cerámica en su mayoría procedentes de contextos domésticos y reutilizadas como contenedores funerarios, colocadas casi siempre en un pozo. Éstas han sido usadas principalmente para el entierro de infantes, hasta menores de 6 años de edad (Isla y Reindel 2006). Por último, las cámaras funerarias o en «barbacoa» son las estructuras funerarias más grandes y mejor construidas; al parecer en ellas fueron enterradas personas de mayor relevancia o jerarquía (Isla y Reindel 2006; Isla 2009; Orefici y Drusini 2003). En el caso de El Trigal la recurrente estructuración de las tumbas en pozo simple se suma al patrón reconocido descrito anteriormente, y ampliamente identificado (cfr. Carmichael 1988: 186; Isla y Reindel 2006: 380; Isla 2009: 129). Sin embargo, la presencia de una tumba en «bota» (ETU 13) en la necrópolis, ausente en la literatura arqueológica para la época Nasca, corresponde a uno de los elementos mencionados que se alejan del patrón regular. Al respecto, si bien este tipo de tumba responde más a una tradición norteña, aunque suelen ser más complejas y elaboradas (Guffroy et al. 1989; Castillo 2000), también se ha documentado en el sur, en el valle de Omo (Moquegua), asociado a la tradición Huaracane, en tiempos pre-Tiwanaku (Goldstein 2000). Goldstein (2000) plantea que este tipo de tumbas en «bota», registradas en el valle de Omo, guarda reminiscencias de las tumbas en forma de «botella» Paracas Cavernas excavadas por Julio C. Tello en Cerro Colorado (Goldstein 2000:351), por lo cual sostiene, junto a otras evidencias, su planteamiento de la interacción de sociedades Paracas-Nasca con las pre-Tiwanaku en el sur altiplánico e interandino. Sin embargo, a diferencia de las tumbas en bota de tradición Huaracane, que presentan entierros colectivos y conjuntos de ajuares significativos (cfr. Goldstein 2000:351-354, Fig. 13 y Fig. 14), aquella encontrada en la necrópolis de El Trigal mantiene el carácter de sepultura individual y está carente de cualquier tipo de ajuar funerario. Otra excepción a la norma que se advierte en El Trigal, se observa en el uso de estructuras en pozo o fosa para el enterramiento del total de individuos infantes y recién nacidos y no en urnas como lo señalan Carmichael (1988: 194) e Isla y Reindel (2006: 379) para poblaciones Nasca.

Otro elemento recurrente en las tumbas Nasca es la presencia de marcadores o señales de tumba, usualmente piedras y/o adobes con barro y en algunos casos una o más varas de madera o cañas colocadas de manera vertical (Carmichael 1988; Isla y Reindel 2006; Orefici y Drusini 2003). En el caso de El Trigal, estos marcadores se adjuntan al patrón registrado, obviamente con las variantes que podrían resultar del tipo de estructuras (en este caso de pozos). No obstante, llama la atención en El Trigal el uso de cantos rodados en su composición, que no han sido descritos hasta el momento en la bibliografía existente, aunque suponemos tácita su presencia. Es interesante, al respecto, la similitud 
existente con las estructuras funerarias que localizó L. Valdez en algunos yacimientos del periodo Intermedio Temprano en Acarí (Valdez 2006). Si bien Valdez señala la adscripción de estos contextos a una tradición local que denomina Huarato, la caracterización de los marcadores o señal de tumbas que encuentra, sumada a las formas de enterramiento de individuos adultos, a la preparación de los muertos y a la recurrente ausencia de ajuares (Valdez 2006: 6-13), no difiere en mucho con las de El Trigal, los cuales mantienen plena asociación con restos materiales Nasca.

Con respecto a los ajuares funerarios Nasca, existe una recurrente presencia de ofrendas, tales como productos orgánicos (alimenticios), objetos de cerámica, líticos y otros artefactos de materiales imperecederos que suelen acompañar a los entierros. La cantidad y calidad de los bienes varía de acuerdo a la complejidad de las tumbas y a los individuos (Carmichael 1988, 1995; Isla y Reindel 2006). Los registros en la necrópolis de El Trigal han permitido constatar un leve alejamiento del patrón funerario normativizado Nasca que señala al menos un elemento de ofrenda en las tumbas (Orefici y Drusini 2003: 118) e inclusive de quienes sugieren la presencia recurrente de la clásica cerámica polícroma como ajuar en éstas (Carmichael 1988: 306). En el caso de El Trigal es casi nula la presencia de ajuares entre los contextos intactos, a excepción de algunos objetos individualizados en algunas tumbas. Es el caso del ornamento de cuentas de Spondylus sp. en la tumba ETU 9 y del collar de conchas de moluscos marinos (Fig. 13) de la tumba ETU 22; ambos ajuares acompañaban a un neonato y a un infante respectivamente. Además, se ha documentado la presencia de una olla llana pequeña con asas que acompañaba a un varón adulto en la tumba ETU 17. Así, sólo tres de las diecisiete tumbas intactas presentan ajuar funerario. Sin embargo, el hallazgo de tres vasijas de cerámica (EOF 1, EOF 2 y EOF 3) depositadas en pozos de forma individual y cercanas a los entierros, podría indicar otro tipo de ofrendas dirigidas, quizá, al conjunto de tumbas de la necrópolis. La probable aportación de ofrendas, externas a las tumbas, forman parte de unas prácticas detectadas en otros yacimientos Nasca (Orefici y Drusini 2003, Isla y Reindel 2006; Silverman 1993) y es un elemento muy ligado al mundo Andino (Murra 2002). Por otro lado, junto a estas escasas evidencias de ajuares y ofrendas, en las capas de la necrópolis donde podrían encontrarse los restos de ajuares de tumbas saqueadas, rotos o esparcidos, el número de productos registrados es muy bajo. Esto indicaría que en las tumbas saqueadas no hubo ni en cantidad ni en calidad un volumen apreciable de ajuares funerarios, ya que, las excavaciones clandestinas, aun habiendo expoliado algunos objetos destacables, siempre dejan un rastro de objetos desechados. Las evidencias nos llevan a plantear que la población de la necrópolis de El Trigal, a pesar de los pocos objetos suntuarios encontrados, no contaba con una riqueza destacable en comparación con otras poblaciones contemporáneas en la zona (cfr. Kroeber y Collier 1988; Orefici y Drusini 2003; Silverman 1993).

El tratamiento funerario de los cuerpos en época Nasca permite reconocer una caracterización en la posición del individuo, recurrentemente sentado con las piernas flexionadas y las manos a la altura del pecho o la cavidad ventral, o recostadas sobre las rodillas (Isla y Reindel 2006), coincidentes con la posición de los entierros registrados en El Trigal. Igualmente, existen registros sobre manipulaciones de cuerpos en contextos Nasca; es el caso concreto de cráneos deformados (Carmichael 1988; Silverman 1993; Williams et al. 2001; inter alii), cabezas cercenadas (Baraybar 1987; Browne et al. 2003; Orefici y Drusini 2003; Silverman 1993, inter alii), individuos decapitados (Conlee 2007; DeLeonardis 2000), cuerpos desmembrados (postmortem) (Carmichael 1988) y evidencias de traumas físicos o agresiones violentas (Kellner 2002; Tomasto 2009). Las evidencias en El Trigal indican la existencia de manipulaciones directas sobre los cuerpos. Una de estas, la deformación intencional del cráneo de tipo anular (Lozada y Buikstra 2002) está presente en cinco individuos analizados en El Trigal: un subadulto (ETU 16) y cuatro adultos (ETU 3, ETU 13, ETU 17 y ETU 18), cuyo grado de deformación varía de leve a pronunciado. Este tipo de deformación craneal en la sociedad Nasca fue un elemento común presente en gran parte de la población (Browne et al. 1993, Carmichael 1988; Coehlo 1972; Silverman 1993; Tomasto 2009; Williams et al. 2001). Sin embargo, estas prácticas no se definen como un patrón determinante de adscripción étnica, sino como un marcador de identidad a un grupo social, en un determinado evento o situación histórica concreta ( $c f r$. Torres-Rouff 2007). De este modo, se enmarca dentro una 
línea político-ideológica discursiva de identidad, socialmente construida e inscrita en el cuerpo. Muchas sociedades prehispánicas la practicaron (Allison et al. 1981), y deformaciones similares a las de Nasca -tipo anular- se han encontrado desde las zonas altiplánicas hasta los valles interandinos de Moquegua (Tiwanaku) (Hoshower et al.1995: Fig. 7) e incluso en la costa norte de Chile (Torres-Rouff 2007: Fig. 2). Estas deformaciones eran irreversibles y se ponían en práctica cuando el individuo era un recién nacido para lograr el moldeado de su cráneo en la edad adulta (Allison et al. 1981); un proceso de transformación que, aunque no existe una clara correlación como causante de posibles patologías, debió causar lesiones físicas y psíquicas en el individuo en el transcurso de su vida.

Otra manipulación que se observa sobre los cuerpos encontrados en la necrópolis, corresponde a un cráneo separado del cuerpo y depositado en urna (ETU 15). El cráneo presenta evidencias de manipulación postmortem, pues se ha detectado una pequeña perforación en el hueso frontal y la ausencia de la base craneal. Estas características sugieren su adscripción al grupo de las denominadas «cabezas trofeo", ampliamente reconocidas en el mundo Nasca (Baraybar 1987; Browne et al. 1993, Coelho 1972; Silverman 1993; Tello 1918; Uhle 1914, Verano 1995, Williams et al. 2001; inter alii), aunque, a diferencia de éstas, no presente indicios claros de uso de posibles aditamentos (p.e. cuerda) ni deformación alguna. Contextos similares - cabezas en urna- se han encontrado en sitios de Chaviña y Tambo Viejo, en Acarí (Coelho 1972; Kowta 1987) y en el complejo monumental de Cahuachi, en el valle de Nasca (Orefici y Drusini 2003; Silverman 1993). Hasta no hace mucho se ha observado una fuerte tendencia a complejizar las interpretaciones en torno al origen, propósito y significado de las denominadas «cabezas trofeo» Nasca (cfr. Forgey y Wlliams 2003), considerando, quizá, que tal complejización ha sido producto de la dificultad existente en demostrar qué existe realmente detrás de las prácticas reconocibles en ellas -tales como «decapitaciones», «conflictos bélicos», «batallas rituales», «cultos a los antepasados» o « ritos de fertilidad agrícola» entre otros (Baraybar 1987; Browne et al. 1993; Carmichael 1995; Verano 1995; DeLeonardis 2000; Conlee 2007; Proulx 1979, 1981, 2001, inter alii)-y las situaciones sociales que las produjeron. Creemos que, más allá de proporcionar una explicación directa de sus orígenes rituales o su obtención mediante prácticas militares, se necesita ver detrás del cristal opaco de la argumentación cosmogónica insustancial con que suele percibirse ¿Qué existe detrás de estas prácticas rituales? y ¿Cuál es la real fundamentación política-ideológica que les dio origen?.

Igualmente, en cuanto a manipulación, el hallazgo de cuerpos desmembrados, individuos sin cabeza y evidencias de agresión con arma (ETU 10B, ETU 20 y ETU 21), nos llevan a plantear, más que un mero tratamiento funerario, la aplicación de políticas de violencia física en las que se inscriben estos cuerpos. Destacan el hallazgo de unas extremidades inferiores aisladas en la tumba ETU 10B, al igual que un infante sin cabeza, de posible cercenamiento postmortem (Godoy 2008), en la tumba ETU 20 -en una estructura funeraria intacta-. Lo que no deja lugar a dudas y que confirma la práctica de violencia física a las que estuvieron sometidos algunos individuos, es el hallazgo de un cuerpo desmembrado (sin cráneo ni extremidades inferiores) en la tumba ETU 21, en perfectas condiciones de conservación, tanto la estructura funeraria como los restos óseos, y con una punta de flecha clavada a la altura del esternón. En consecuencia, sin pretender inferir una interpretación concluyente sobre estos datos, consideradas las escasas evidencias, pero igualmente sin querer caer en la tentadora facilidad con la que se suele explicar lo inexplicable como efecto de actos rituales, no podemos dejar de lado que evidencias de violencia en los cuerpos forman parte del registro arqueológico de esta sociedad (cfr. Kellner 2002; Tomasto 2009). Así, cuerpos con indicios claros de decapitación, aunque muy pocos, se han registrado en el valle de Aja (Conlee 2007) e Ica (DeLeonardis 2000). A ellos se suman, de manera indirecta, el creciente número de hallazgos de las denominadas «cabezas trofeo» (Baraybar 1987; Browne et al. 1993, Coelho 1972; Silverman 1993; Tello 1918; Uhle 1914, Williams et al. 2001; inter alii) y la casi generalizada representación iconográfica de este motivo sobre los distintos soportes materiales (Fig. 9a) (Blasco y Ramos 1980; Carmichael 1994; Proulx 2001, 2006; Roark 1965; inter alii), e incluso de escenas naturales de los propios actos de decapitación (DeLeonardis 2000: 377-378 Fig. 14-15; Verano 1995: 215 Fig. 11). 
En general, a diferencia de otros contextos de restos humanos incompletos procedentes de yacimientos de época Nasca (Carmichael 1988; Kroeber y Collier 1998; reportes citados en DeLeonardis 2000: 373-374, inter alii), que originaron una producción de inferencias no contrastables y una desconfianza del dato empírico, las tumbas selladas e intactas de El Trigal, cuyo contenido presentó cuerpos desmembrados y una "cabeza trofeo», certifican la fiabilidad de los datos y desvirtúan cualquier inferencia de difícil contrastación acerca de los mismos (p.e. posibles remociones sufridas en épocas prehispánicas (Carmichael 1988, 1995) e incluso en épocas recientes). Si bien no queda clara la naturaleza de los desmembramientos en El Trigal, los exámenes osteológicos preliminares señalan que éstos se produjeron no sólo previo enterramiento, sino también mientras los cuerpos aún conservaban tejido blando (Godoy 2007, 2008). Por tanto, tales acciones dejan un estrecho margen de tiempo desde el acontecimiento que desencadenó la muerte de los individuos. A estas características se suman la lesión por agresión con armamento (punta de flecha) en uno de estos cuerpos sin cabeza, que deja al descubierto el ejercicio de la violencia que padeció una parte de la población aquí enterrada. Violencia que se extendió a otras comunidades Nasca, tal como se observa en recientes exámenes osteológicos de una muestra importante de individuos de poblaciones contemporáneas y cercanas a nuestra área de estudio (Kellner 2002; Tomasto 2009).

Por último, el hallazgo de una serie de depósitos y hoyos de poste concentrados principalmente en el área intermedia de la necrópolis de El Trigal, además del registro de fogones localizados de manera dispersa, permite señalar la existencia de espacios contiguos a las áreas funerarias ligadas a posibles actividades rituales y otras no necesariamente asociadas a las mismas. Así, cabe la posibilidad de sugerir que algunas de las actividades sociales que se llevaron a cabo en estos espacios alternos pudieron formar parte también de prácticas económicas ligadas a zonas de procesado y almacenamiento (depósitos), además de áreas para la cocción de alimentos y/o resguardo. A ellos se suman los hallazgos de restos artefactuales, en un porcentaje mínimo, como manos de moler, fragmentos de vajilla llana e incluso restos de obsidiana; lamentablemente en muchos de ellos no queda claro su asociación estratigráfica, por lo cual podrían formar parte, también, de componentes provenientes de tumbas saqueadas. No es extraño para el caso Nasca que espacios habitacionales se hayan establecido contiguos a áreas funerarias o, de manera inversa, cementerios cerca de espacios habitacionales (cfr. Silverman y Proulx 2002: 109-112).

\section{CONSIDERACIONES FINALES}

El registro arqueológico de la necrópolis de El Trigal nos aporta nuevas evidencias acerca de la naturaleza de las prácticas funerarias en tiempos Nasca. La heterogeneidad de los entierros documentados en El Trigal, resalta matices excepcionales que en algunos casos se alejan del patrón generalizado Nasca (Carmichael 1988, 1995; Isla y Reindel 2006; Isla 2009). A nivel estructural, el registro de una tumba en «bota» llama la atención por su ausencia en la literatura arqueológica de esta sociedad y su probable vinculación con tradiciones culturales del sur andino (Huaracane) (Goldstein 2000), contemporáneas al periodo Nasca Temprano. Aun con más razón, este hallazgo cobra interés por la implicación que tiene este tipo de tumbas en las relaciones de interacción de sociedades Paracas-Nasca con las sociedades pre-Tiwanaku en el valle de Omo (Moquegua).

Del mismo modo, en cuanto al tratamiento de cuerpos, el registro de entierros de infantes y neonatos en pozo no coincide con el alto índice de entierros en urna que proporcionan los reportes para las tumbas de infantes Nasca (Carmichael 1988, 1995; Isla y Reindel 2006). La escasa presencia de ajuares señala una diferencia considerable con respecto a los contextos funerarios Nasca, donde hasta en los entierros más pobres se colocaba una vasija de cerámica (Orefici y Drusini 2003). Esto indicaría una pobreza generalizada entre la población de esta necrópolis, aunque el hallazgo de objetos ornamentales, de mayor valor por ser de material de difícil obtención (moluscos marinos trabajados), en tumbas de infantes (ETU 9 y ETU 22), se puede considerar un hecho relevante de apropiación de bienes suntuarios por parte de un sector de la población. Siendo además éstos individuos aún no 
productores, enfatiza la existencia de derechos hereditarios, lo que apuntaría la inclusión de grupos propietarios en el seno de la comunidad de El Trigal, a pesar de la pobreza detectada.

En cuanto a los hallazgos de una cabeza cercenada, cuerpos sin cabeza, cuerpos desmembrados y con evidencia de agresión con arma, dibuja un panorama muy singular sobre los cuerpos enterrados en esta necrópolis, indicando su vinculación con prácticas de violencia física en esta sociedad (Kellner 2002; Tomasto 2009). Y aunque la naturaleza de estos cuerpos violentados no se aleja de la norma establecida (cfr. Carmichael 1988, 1995; Conlee 2007; DeLeonardis 2000; Kroeber y Collier 1988; Kellner 2002; Tomasto 2009), llama la atención la variedad y concentración de los mismos en un área de cementerio muy reducida, algo excepcional en los registros funerarios Nasca.

La heterogeneidad de los contextos documentados en el registro arqueológico de la necrópolis de El Trigal, con respecto a los patrones atribuidos a la sociedad Nasca, señalan particularidades importantes en su lectura y abren algunas interrogantes para su interpretación. Así, de acuerdo a la naturaleza singular de los entierros, junto a los planteamientos iniciales que esboza Silverman (1993) sobre la identificación de entierros que se alejan de los patrones reconocidos Nasca («bab death») ¿Quizá la necrópolis de El Trigal fue un espacio donde se enterraron individuos por cometer «acciones punitivas», «delincuentes», «enemigos», «extranjeros», «victimas de sacrificio», etc.?. Igualmente, frente a las evidencias de prácticas de violencia física (cabezas cercenadas, cuerpos sin cabeza, desmembrados y con agresión por armamento) detectadas en El Trigal y el empobrecimiento que muestran las tumbas halladas, contemporáneas a la emergencia del complejo monumental de Cahuachi, indican que ¿Se trataría quizá de una comunidad local dominada y coaccionada por la emergente élite Nasca de Cahuachi?.

Al respecto, nuestras primeras lecturas esbozan que el poblado enterrado en El Trigal no contaba con una riqueza destacable en comparación con otros, quizá, de mayor jerarquía o mejor posición socio-económica, coetáneos en la zona (cfr. Kroeber y Collier 1988; Orefici y Drusini; Silverman 1993). Esas diferencias se hacen más expresivas con la emergencia del complejo monumental de Cahuachi, como centro político-ideológico en el valle de Nasca (Bachir 2007; Llanos 2010). Distante de ser sólo un «centro de culto» o de "peregrinación» (Silverman 1993; Vaughn y Van Gijseghem 2007) y de considerarse «vacío» (Silverman 1993), recientes investigaciones (cfr. Bachir 2007; Llanos 2010) plantean que en Cahuachi habitó un grupo dirigente que centralizó el poder político y económico regulando el control de la producción en la zona, gestionando la distribución y el acceso a lo producido en beneficio propio. De este modo, este grupo dominante, reproduciría relaciones asimétricas, a nivel económico, político e ideológico, entre las comunidades de la región con el fin de afianzar y mantener el orden social establecido. Las evidencias de empobrecimiento que muestran las tumbas halladas en la necrópolis de El Trigal -correspondiente a esta época- podrían indicar que la comunidad asentada en esta parte del valle se vio forzada a transferir una parte destacable de la riqueza producida al grupo dominante de Cahuachi (Castro Martínez, De La Torre Zevallos y Escoriza 2008, 2009).

Es en este sentido que, el interés por mantener esas asimetrías sociales, que beneficiaban a este grupo minoritario (dirigente) de la población, propició la recreación de manifestaciones ideológicas de naturalización y legitimación del orden establecido mediante las prácticas rituales. Así, las denominadas «cabezas trofeo» formaron parte de esos rituales, junto a otros, dentro del marco de una política de violencia física, muy arraigada, y en algunos casos ligada a las prácticas de decapitación, tal como se puede observar en algunas representaciones naturalistas y en la frecuente estilización de las denominadas «cabezas trofeo» de la iconografía Nasca. La decapitación, o cercenamiento de cabezas, el desmembramiento de cuerpos, y la evidencia de agresiones con armas, documentados también en la necrópolis de El Trigal, quizá no sólo tuvieron un origen bélico o ceremonial, sino además una motivación sancionadora, punitiva e intimidatoria. No es extraño que las representaciones simbólicas (iconográficas) e ideológicas de estas prácticas, además de las propias cabezas cercenadas, a través de los diferentes medios y soportes materiales (Fig. 9b), permitieran instalar una especie de comunicación visual y/o propaganda política que, mediante la religión, naturalizaría y legitimaría todo acto violento en la vida social de las comunidades explotadas, víctimas del poder institucionalizado. 
En la espera de nuevas investigaciones que aporten más datos y contribuyan a clarificar mejor el panorama, las evidencias documentadas hasta el momento en El Trigal aportan elementos importantes que permiten señalar la existencia de relaciones sociales asimétricas entre poblados coetáneos y el ejercicio de actos de violencia física por una parte de la población. Violencia que, principalmente, estuvo dirigida a intimidar y coaccionar a las comunidades asentadas en el valle de Nasca, durante el periodo Nasca Temprano, para subordinarlas al poder político-ideológico centralizado de Cahuachi, tal como sugieren los entierros registrados en El Trigal.

\section{Agradecimientos}

Los trabajos de excavación en la necrópolis de El Trigal se realizaron gracias al financiamiento otorgado por el Ministerio de Cultura de España (Programa de Proyectos Arqueológicos en el Exterior 2005-2010) y de la Agència de Gestió d'Ajuts Universitaris i de Recerca de la Generalitat de Catalunya (Programa Excava 2006-2009), y los permisos concedidos por el entonces Instituto Nacional de Cultura del Perú. Asimismo, quiero agradecer al equipo investigador inicial del Proyecto Arqueológico La Puntilla: Pedro Castro, Nicolau Escanilla, Trinidad Escoriza, M Concepción Godoy, Barbara Lapi, Israel Navarro, François Virebayre y Julio Zavala, además del equipo de apoyo que nos ha acompañado a lo largo de estos años en la costa sur del Perú.

\section{BibliografíA}

ALLISON, Marvin, Enrique GERSZTEN, Juan MUNIZAGA, Calogero SANTORO y Guillermo FOCACCI

1981 «La práctica de la deformación craneana entre los pueblos andinos precolombinos». Chungará: Revista de Antropología Chilena, 7: 238-260.

BACHIR, Aicha

2007 «Dinámica y desarrollo de un centro ceremonial andino. El caso de Cahuachi». Arqueología y Sociedad, 18: 69-94.

BARAYBAR, José. P.

1987 «Cabezas trofeo Nasca: nuevas evidencias». Gaceta Arqueológica Andina, 15: 6-10.

BLASCO, M. Concepción y Luis RAMOS

1980 Cerámica Nasca. Seminario Americanista de la Universidad de Valladolid. Serie Americanista 13, Valladolid.

BROWNE, David, Helaine SILVERMAN y Rubén GARCÍA

1993 «A cache of 48 Nasca trophy heads from Cerro Carapo, Peru». Latin American Antiquity, 4 (3): 274-294.

CARMICHAEL, Patrick

1988 Nasca mortuary customs: Death and ancient society on the south coast of Peru. PhD Dissertation, Department of Archaeology, University of Calgary, Calgary.

1995 «Nasca burial patterns: social structure and morturary ideology». En: Tombs for the living: Andean Mortuary Practices, Dillehay, T. (Ed.), pp: 161-188. Dumbarton Oaks, Washington D.C.

CASTILLO, Luis J.

2000 «La presencia de Wari en San José de Moro». Boletín de Arqueología PUCP 4, 143-179.

CASTRO MARTÍNEZ, Pedro, Juan C. DE LA TORRE ZEVALLOS y Trinidad. ESCORIZA

2008 «Proyecto La Puntilla 2007. Prácticas Sociales y Producción de la Vida Social en los Horizontes del Formativo-Paracas.Costa Sur del Perú». En: Informes y Trabajos del Instituto del Patrimonio Cultural de España 1. Ministerio de Cultura de España. Vol. no 1, pp: 125-131. Madrid.

2009 «Proyecto La Puntilla (Nasca, Ica, Perú). Avances de las investigaciones 2008». En: Informes y Trabajos del Instituto del Patrimonio Cultural de España 3. Ministerio de Cultura de España. Vol. no 3, pp: 181-189. Madrid.

2011 «Proyecto La Puntilla (Nasca, Ica, Perú). Excavaciones en el área del Edificio de los Patios de El Trigal». En: Informes y Trabajos del Instituto del Patrimonio Cultural de España 5. Ministerio de Cultura de España. Vol. n 5, pp: 258-267. Madrid. 
COELHO, Vera P.

1972 Enterramentos de cabeças de cultura Nasca. Department of Communication and Arts. Ph. D. Dissertation. Universidad de Sao Paulo.

CONLEE, Christina

2003 «Local Elites and the Reformation of Late Intermediate Period Sociopolitical and Economic Organization in Nasca, Peru». Latin American Antiquity, 14 (1): 47-65

2007 «Decapitation and Rebirth: a headless burial from Nasca, Peru». Current Anthropology, 48 (3): 438-445.

DE LA TORRE ZEVALLOS, Juan C.

2005 «Arqueología y sociedad en la costa sur del Perú: Sujetos sociales y espacios domésticos en la sociedad Paracas (1100-100 ANE). Excavaciones Arqueológicas en La Puntilla». En: América Latina, realidades diversas. Aula Oberta 2001-2005. L Mameli y E. Muntañola, eds., (2005) Institut Catalá de Cooperació Iberoamericana-Centre d'Estudis Internacionals i Interculturals - UAB, Barcelona: pp. 76-90.

2012 Hallazgo de una cabeza cercenada («cabeza trofeo») en el valle de Nasca (Perú): Detrás del ritual y la víctima. Manuscrito en poder del autor.

DE LA TORRE ZEVALLOS, Juan C. y Pedro CASTRO MARTíNEZ

2006 Proyecto Arqueológico La Puntilla (Nasca, Perú) 2005. Sujetos Sociales y Ámbitos Domésticos en la Sociedad Paracas. Informe Final 2005, Instituto Nacional de Cultura del Perú.

2007 Proyecto Arqueológico La Puntilla (Nasca, Perú) 2006. Sujetos Sociales y Ámbitos Domésticos en la Sociedad Paracas. Informe Final 2006, Instituto Nacional de Cultura del Perú.

DE LA TORRE ZEVALLOS, Juan C. y Hendrik VAN GIJSEGHEM

2005 «Excavaciones en La Puntilla (1300-100 a.n.e.): Arqueología en la costa sur del Perú». Revista de Arqueología del Siglo XXI, 286: 22-31.

DELEONARDIS, Lisa

2000 «The body context: interpreting early Nasca decapitated burials». Latin American Antiquity, 11 (4): 363-386.

FORGEY, Kathleen y Sloan R. WILLIAMS

2003 «Cabezas trofeo Nasca: evidencias osteológicas y arqueológicas de la colección Kroeber». Revista Andina, 36: 237-261.

2005 «Were Nasca trophy heads war trophies or revered ancestors?». Interacting with the Dead: Perspectives on Mortuary Archaeology for the New Millenniun. Ed. G. F. M. Rakita, J. E. Buikstra, L. A. Beck y S. R. Williams, pp: 251-276. University Press of Florida. Gainesville.

GODOY, M. Concepción

2007 «Análisis bioantropológico preliminar de los contextos funerarios de la Temporada 2006 en El Trigal (Apéndice 5)». En: De La Torre Zevallos, J. C. y Castro Martínez, P. V. Proyecto Arqueológico La Puntilla (Nasca, Perú) 2006. Sujetos Sociales y Ámbitos Domésticos en la Sociedad Paracas. Informe Final 2006. Instituto Nacional de Cultura del Perú.

2008 «Análisis bioantropológico preliminar de los contextos funerarios de la Temporada 2007 en El Trigal (Apéndice 6)». En: Castro Martínez, P.V., De La Torre Zevallos, J.C., Godoy, M.C., Lapi, B., Navarro, I., Virebayre, F y Zavala J.C. Proyecto Arqueológico La Puntilla (Nasca, Perú) 2007. Sujetos Sociales y Ámbitos Domésticos en la Sociedad Paracas. Informe Final 2007. Instituto Nacional de Cultura del Perú.

GOLDSTEIN, Paul

2000 «Exotic Goods and Everyday Chiefs: Long-Distance Exchange and Indigenous Sociopolitical Development in the South Central Andes». Latin American Antiquity, 11 (4): 335-361.

GUFFROY, Jean, Peter KAULICKE y Krzystof MAKOWSKY

1989 «La prehistoria del departamento de Piura: Estado de los conocimientos y problemática». Bulletin de l'Institut Français d'Études Andines, 18 (2): 117-142.

HOSHOWER, Lisa, Jane BUIKSTRA, Paul GOLDSTEIN y Ann WEBSTER

1995 «Artificial cranial deformation at the Omo M10 site: A Tiwanaku Complex from the Moquegua Valley, Peru». Latin American Antiquity, 6 (2): 145-164. 
ISLA, Johny

1992 «La ocupación nasca en Usaca». Gaceta Arquelogica Andina, 22: 119-151.

2009 «From Hunters to Regional Lords: Funerary Practices in Palpa, Peru». En: New Technologies for Archaeology: Multidisciplinary Investigations in Palpa and Nasca, Peru. Reindel, M.y G. Wagner. (eds.), pp: 119-139. Heidelberg, Berlin, New York.

ISLA, Johny, Mario RUALES y Andrés MENDIOLA

1984 «Excavaciones en Nasca: Pueblo Viejo, sector X3». Gaceta Arqueológica Andina, 12: 8-11.

ISLA, Johny y Markus REINDEL

2006 «Burial patterns and sociopolitical organization in Nasca 5 society». En: Andean Archaeology III: North and South. W. H. Isbell \& H. Silverman (eds.): 374-400; New York: Springer Publishing.

KELLNER, Corina

2002 Coping with environmental and social challenges in Prehistoric Peru: Bioarchaeological analyses of Nasca populations. PhD Dissertation, University of California, Santa Barbara.

KNUDSON, Kelly J., Sloan R. WILLIAMS, Rebecca OSBORN, Kathleen FORGEY, y Patrick R. WILLIAMS

2009 «The geographic origins of Nasca trophy heads using strontium, oxygen, and carbon isotope data». Journal of Anthropological Archaeology, 28: 244-257.

KOWTA, Makoto

1987 An Introduction to the Archaeology of the Acari Valley in the south coast region of Peru. California Institute for Peruvian Studies. Sacramento.

KROEBER, Alfred

1927 «Coast and Highland in Prehistoric Peru». American Anthropologist, New Series, Vol. 29, No. 4: 625653

1944 Peruvian archaeology en 1942. Viking Fund Publications en Anthropology, n. 4, Wenner-Gren Foundation, New York.

1956 Toward definition of the Nazca style. American Archaeology and Ethnology, 43 (4): 327-432.

KROEBER, Alfred y Donald COLLIER

1998 The Archaeology and Pottery of Nazca, Peru. Alfred L. Kroeber's 1926 Expedition. Walnut Creek, CA: AltaMira Press.

LLANOS, Oscar D.

2010 «Cahuachi: residencia y paisaje sacralizado de un centro político Nazca». Revista Española de Antropología Americana, 40 (1): 27-51.

MURRA, John

2002 El Mundo Andino: Población, medio ambiente y economía. Instituto de Estudios Peruanos. Lima

OREFICI, Giuseppe y Andrea DRUSINI

2003 Nasca. Hipótesis y evidencias de su desarrollo cultural. Centro Italiano Studi e Ricerche Archeologiche Precolombiane (CISRAP). Lima.

PROULX, Donald A.

1971 «Headhunting in Ancient Peru». Archaeology, 24 (1): 16-21.

1989 «Nasca trophy heads: victims of warfare or ritual sacrifice?». En: Cultures in Conflict: Current Archaeological Perspectives (D. C. Tkaczuk y B. C. Vivian, eds.), pp: 73-85. Archaeological Association of the University of Calgary.

2001 «Ritual uses of trophy heads in ancient Nasca society». En: Ritual Sacrifice in Ancient Peru. E. Benson y A. Cook, eds., pp: 119-136. University of Texas Press. Austin.

2006 A sourcebook of Nasca ceramic iconography: Reading a culture through its art. University of Iowa Press, Iowa City.

REINDEL, Markus y Günther WAGNER (eds.)

2009 New Technologies for Archaeology: Multidisciplinary Investigations in Palpa and Nasca, Peru, Springer, Heidelberg, Berlin, New York.

ROARK, Richard

1965 «From monumental to proliferous in Nasca pottery». Ñawpa Pacha, 3: 1-92. 
ROBINSON, David A.

1957 An Archaeological survey of the Nasca Valley, Peru. Master's Thesis in Anthropology, Stanford University.

ROWE, John H.

1956 "Archaeological Explorations in Southern Peru, 1954-55. Preliminary Report of the Fourth University of California Archaeological Expedition to Peru». American Antiquity, Vol. 22 (2): 135-151.

SILVERMAN, Helaine

1993 Cahuachi in the Ancient Nasca World. University of Iowa Press, Iowa City.

SILVERMAN, Heleine y Donald A. PROULX

2002 The Nasca. Blackwell Publishers, Malden.

STRONG, William D.

1957 «Paracas, Nazca and Tiahuanacoid Cultural Relationships en South Coastal Peru». American Antiquity, Vol. 22, 4(2). Memoirs 13.

TELLO, Julio C.

1918 «El uso de las cabezas humanas artificialmente momificadas y su representación en el antiguo arte peruano». Revista Universitaria, 2: 477-533.

TELLO, Julio C. y Toribio MEJÍA XESSPE

1967 «Historia de los Museos Nacionales del Perú 1822-1946». Arqueológicas, 10.

TOMASTO, Elsa

2009 «Talking Bones: Bioarchaeological analysis of individuals from Palpa». En: New Technologies for Archaeology: Multidisciplinary Investigations in Palpa and Nasca, Peru. Reindel, M. y G. Wagner (eds.), pp: 141-158. Heidelberg, Berlin, New York.

TORRES-ROUFF, Christina

2007 «La deformación craneana en San Pedro de Atacama». Estudios Atacameños: Arqueología y Antropología Surandinas, 33: 25-38.

VALDEZ, Lidio M.

2006 «Los vecinos de Nasca: entierros de la tradición Huarato del valle de Acarí, Perú». Bulletin de l'Institut Français d'Études Andines, 35 (1): 1-20.

VAN GIJSEGHEM, Hendrik

2004 Migration, agency, and social change on a prehistoric frontier: The Paracas-Nasca transition in the southern Nasca drainage, Peru. PhD Dissertation, University of California, Santa Bárbara.

VAUGHN, Kevin J. y Hendrik VAN GIJSEGHEM

2007 "A compositional perspective on the origins of the "Nasca cult» at Cahuachi». Journal of Archaeological Science 34: 814-822.

VERANO, John W.

1995 "Where do they rest? The treatment of human offerings and trophies in ancient Peru». En: Tombs for the Living: Andean Mortuary Practices (T. D. Dillehay, ed.), pp: 189-227. Dumbarton Oaks Research Library. Washington, D.C.

2001 «The physical evidence of human sacrifice in ancient Peru». En: Ritual Sacrifice in Ancient Peru. E. Benson y A. Cook, eds., pp: 165-184. University of Texas Press. Austin.

2003 «Mummified trophy heads from Peru: diagnostic features and medicolegal significance». Journal of Forensic Sciences, 48 (3): 525-530.

WILLIAMS, Sloan R., Kathleen FORGEY y Elizabeth KLARICH

2001 «An osteological study of the Nasca trophy heads collected by A. L. Kroeber during the Marshall Field Expeditions to Peru (1925-1926)». Fieldiana Anthropology, Series 33.

UHLE, Max

1914 «The Nazca pottery of ancient Peru». Proceedings of the Davenport Academy of Sciences, 3: 1-16.

URÍZAR, Marcela y Daniel CASTELLANOS

2009 «Análisis bioantropológicos de los contextos funerarios del Proyecto La Puntilla 2006-2007 (Apéndice 5)». En: Castro Martínez, P. V., De La Torre Zevallos, J. C. y Escoriza T. Proyecto Arqueológico La Puntilla (Nasca, Perú) 2009. Sujetos Sociales y Ámbitos Domésticos en la Sociedad Paracas. Informe Final 2008. Instituto Nacional de Cultura del Perú. 